\title{
El Trienio Liberal en el Virreinato peruano: los ayuntamientos constitucionales de Arequipa, Cusco y Huamanga, 1820-1824 ${ }^{1}$
}

por

\author{
Núria Sala i Vila \\ Universitat de Girona
}

\begin{abstract}
El artículo profundiza en aspectos desconocidos de lo que fue la reimplantación del gobierno representativo en el Virreinato del Perú durante el Trienio Liberal. Para ello se seleccionan tres ciudades, el Cusco, Huamanga y Arequipa, que se mantuvieron hasta muy tarde leales a la Corona. La consulta de documentación generada por las tres corporaciones ha permitido reconstruir tres ejemplos de poder local a través de los procesos electorales, la composición de los ayuntamientos y el análisis de sus competencias. Se demuestra que el virrey La Serna gobernó según la Constitución de 1812 y se pone de manifiesto que existieron cambios y continuidades entre ayuntamientos españoles y municipalidades peruanas, porque permanecieron algunos actores y fórmulas de las instituciones hispanas.

Palabras Clave: Trienio Liberal; Perú; Ayuntamientos Constitucionales; Arequipa; Cusco; Huamanga.
\end{abstract}

El Trienio Liberal (1820-1823) supuso el retorno del virreinato peruano a los principios liberales establecidos en la Constitución de 1812, vigentes hasta 1814, con lo que comportaba de cambios profundos en la concepción del Estado español concebido como representación de la Nación y sustentado sobre la base de la división de poderes y una nueva organización territorial. Entre las reformas sustanciales que se produjeron, aparte de las ya citadas, junto a la liquidación paulatina del entramado legal absolutista y la libertad de imprenta ${ }^{2}$, no fue el menor la nueva terminología que se impuso, por la cual se difundie-

1 Investigación realizada dentro del proyecto I+D Tiempos de desconcierto. Política y sociedad en la Independencia del Perú, 1820-1824, Referencia HAR2008-03259/HIST, financiado por el Ministerio de Ciencia e Innovación de España.

2 Peralta, 2009. 
ron expresiones como Banderas Nacionales, Audiencia Nacional, Caja Nacional, Ejército Nacional, Milicias Nacionales, expresión política y militar de la emanación de todo poder de la Nación. Ello nos lleva a pensar que en las mentes de la época se fue gestando un enfrentamiento entre nacionales y patriotas, o lo que era lo mismo en el marco de dos proyectos liberales contrapuestos. El retorno al absolutismo en 1824, volvería a convertir las luchas por la Independencia en un enfrentamiento entre un Estado colonial de Antiguo Régimen y el sistema liberal independentista.

La cuestión americana había sido sustancial en los debates de la Constitución de 1812, sobre todo en lo relativo a la representación que debían tener las gentes y los territorios de Ultramar. Aunque en 1820 buena parte de ellos se habían independizado, restaban bajo el dominio español los virreinatos del Perú, de la Nueva España y las Antillas. Y si bien al promediar el Trienio Liberal una parte considerable del Perú, ya independiente, caminaba indefectiblemente hacia la construcción de un Estado republicano, los territorios del sur y Charcas siguieron bajo el dominio español hasta fines de 1824. En general, la historiografía que ha analizado la actuación del virrey La Serna ha dado por supuesto que atenuó, en lo posible, la vigencia de la Constitución de 1812. Tal supuesto inspiró buena parte de las memorias y alegatos de los militares derrotados en Ayacucho, cuando de regreso a España, de nuevo absolutista, buscaron redimir su conducta militar y su vinculación liberal.

Nuestra propuesta es analizar la aplicación de los patrones del liberalismo hispano en las provincias del Virreinato del Perú que siguieron bajo el control realista, para lo cual proponemos una serie de reflexiones sobre las características de la organización política local, y cuando sea pertinente provincial, en las ciudades de Arequipa, Cusco y Huamanga. El análisis se basa sobre todo en la consulta de fuentes oficiales relacionadas con el gobierno local español entre 1820 y 1824 y en especial de los libros de actas de los ayuntamientos constitucionales de las tres ciudades. Estos no se han conservado en su totalidad, es muy posible que debido a las propias contingencias de la guerra de Independencia, y solo ha sido posible localizar el de 1824 para Arequipa ${ }^{3}$, los correspondientes a 1822-1824 para el $\mathrm{Cusco}^{4}$ y el de 1822-1825 para el caso de Huamanga 5 .

3 Archivo Municipal de Arequipa (en adelante AMA), Libros de Actas del Cabildo de Arequipa (en adelante LACA), n. ${ }^{\circ} 30$ 1824-1825.

4 Archivo Regional del Cusco (en adelante ARC), Libros de Actas (en adelante LA), Libro 32, Libro de actas del Ayuntamiento del Cusco 1822-24; Libro 33, Libro de actas del Ayuntamiento del Cusco 1824.

5 Biblioteca Nacional del Perú (en adelante BNP), Manuscritos República (en adelante 
Arequipa, Cusco y Huamanga fueron sedes de Obispado y cabeza de sus respectivas intendencias. En Cusco se constituyó en 1784 la Audiencia homónima y se convertiría en sede del gobierno virreinal desde finales de 1821, tras el repliegue de Lima a la sierra del virrey La Serna y el ejército español. Las tres ciudades fueron, junto con sus zonas circundantes, el eje de una serie de movimientos que condicionaron la larga coyuntura política cuyo inicio cabe situar en la Gran Rebelión de Túpac Amaru (1780-1783), seguida por el ciclo convulsivo abierto por el vacío de poder que supuso el traslado forzado a Francia de Fernando VII - Junta Tuitiva de La Paz (1809), rebelión de los Angulo y Pumacahua (1814-1816) y las sucesivas campañas rioplatenses para hacerse con el control de Charcas- . Posteriormente a los hechos analizados en este texto, la región sería el escenario en que se desarrollaría la breve Confederación Perú-Boliviana (1836-1839). Tal realidad permite apuntar la existencia en el denominado sur andino peruano de un proyecto alternativo al defendido por las autoridades virreinales y las elites limeñas, en demanda de una mayor autonomía frente al centralismo capitalino ${ }^{6}$.

Las características económicas y sociales de las tres ciudades, Arequipa, Cusco y Huamanga, las señalan como el centro de amplios ejes económicos y productivos. Arequipa irradiaba un amplio circuito mercantil que articulaba los puertos de la costa sur del Perú y los valles costeños productores de aguardientes con los centros urbanos y mineros de Cusco, el Collao y Charcas ${ }^{7}$. Cusco era el centro de una amplia zona agraria y ganadera de una gran diversidad ecológica que le permitía disponer de productos altoandinos y tropicales, con una amplia capacidad manufacturera textil —obrajes y chorrillos - dirigida a surtir la amplia demanda minera regional y hacia el Collao, Oruro y Poto$\mathrm{si}^{8}$. La matrícula de gremios de Ayacucho ${ }^{9}$ de 1827 , cuyo objetivo era reordenar la contribución urbana, registró 1.240 artesanos para una población de alrededor de 10.000 habitantes, lo que muestra su «clara faz de ciudad de artesanos y comerciantes mestizos», en que destacaban los comerciantes de gana-

MR), D 10006, Libro de Cabildos de la ciudad de Huamanga, 29 de octubre de 1822. En carátula: n. ${ }^{\circ} 40$, desde octubre de 1822 hasta junio de 1825.

6 Fisher, 1979.

7 Brown, 2008. Chambers, 2003. Condori, 2010.

8 Escandell, 1997. Morner, 1978. Walker, 1999.

9 Huamanga pasó a denominarse Ayacucho tras la Independencia. Hoy día, a pesar que Ayacucho sigue siendo su nombre oficial, se tiende de forma coloquial a diferenciar la ciudad de Huamanga de la región de Ayacucho. Nosotros nos referimos a Huamanga para el periodo colonial y a Ayacucho para la etapa republicana. 
do, panaderos y tejedores ${ }^{10}$, cuya producción sobre todo textil se dirigía a los mercados mineros emergentes de Cerro de Pasco.

Si bien la llegada de San Martín al Perú desencadenó su independencia, durante los cuatro años siguientes la costa y sierra sur fueron el escenario militar en que se dirimió el final del dominio español sobre el continente americano. A finales de 1820, Huamanga fue ocupada brevemente por las tropas comandadas por el general independentista Álvarez de Arenales. Poco sabemos de las posiciones políticas asumidas por sus habitantes, quizás el caso que más ha llamado la atención fue el de su obispo, Pedro Martínez de Cos, quien, refugiado en Lima, ya no regresaría a la ciudad, y después de serios enfrentamientos con San Martín, sería deportado a España, tras lo que fue nombrado obispo de Puerto Rico ${ }^{11}$. Tras ese episodio, la región ayacuchana permanecería fiel al dominio colonial español, aunque fue el escenario de fuertes tensiones, en las que destacaron posiciones insurgentes entre su población indígena rural $^{12}$.

Arequipa fue ocupada por los patriotas en el breve lapso de tiempo de 39 días, tras la entrada en la ciudad de Antonio José de Sucre el 31 de agosto de 1823, para luego volver al control de las tropas hispanas. Sería la última gran ciudad peruana en proclamar la independencia en febrero de 1825, un mes después del Cusco.

\section{LA ORGANIZACIÓN PROVINCIAL Y MUNICIPAL DURANTE EL LIBERALISMO HISPANO (1812-1814 Y 1820-1823/4)}

En los territorios americanos que permanecieron bajo dominio español y en lo que concernía al gobierno regional y local, el breve periodo que fue de 1820 a 1824 se caracterizaría por continuos cambios legislativos y administrativos. La novedad respecto a la etapa 1812-1814 fue la entrada en vigor de la Instrucción para el Gobierno Económico Político de las Provincias de 23 de junio de $1813^{13}$.

10 González, E., Gutiérrez, Y. y Urrutia, J., 1995: 91-92.

11 Hernández, 2008.

12 Igue, 2008.

13 ARC, Real Audiencia, Administrativo, legajo 176, 1821, Oficios de José de la Serna a la Audiencia Nacional del Cusco, Lima, 9 de febrero de 1821, adjuntando ejemplares de la reimpresión de la Constitución de 1812, del Reglamento Instrucción para el Gobierno económico Político de las Provincias de 23 de junio de 1813 y del Reglamento de Tribunales - debemos presuponer que se trataba de una referencia coloquial del Reglamento de las Audiencias y Juzgados de primera instancia de 9 de octubre de 1812-. 
El liberalismo doceañista organizó la administración regional y local sobre la base del reconocimiento de la existencia de provincias y pueblos. El modelo político basado en la división de poderes supuso la desaparición del sistema de intendencias ${ }^{14} \mathrm{y}$ de los cabildos, instituciones sustituidas en las provincias por el Jefe Político Superior y por la Diputación Provincial, y en los pueblos de más de 1.000 almas por ayuntamientos constitucionales. Solo el primero era un cargo sujeto a nombramiento gubernativo, los otros dos eran órganos colegiados electos. Además se preveía la introducción de autoridades específicas para temas de hacienda, militares y judiciales.

El Jefe Político mantuvo competencias gubernativas, de promoción del progreso, así como también de tutela y nexo entre las corporaciones representativas provinciales y locales, ya que no se contemplaba la comunicación directa entre la diputación provincial y los ayuntamientos ${ }^{15}$. Y por fin se ocupaba de la vigilancia y aprobación de los procesos electorales. A tenor de las crecientes dificultades bélicas terminó asumiendo las competencias militares y, en algún caso las de hacienda. En el Perú, lo antedicho comportó que las autoridades regionales continuaran al frente de sus demarcaciones, pero que detentaran un puesto que cambiaba de denominación y de competencias. En Arequipa Juan Bautista de Lavalle fue intendente desde 1817, jefe político superior de la provincia durante la vigencia del segundo liberalismo y de nuevo intendente a partir de marzo de 1824, cuando se retornó al absolutismo. En el Cusco, Pío Tristán era intendente y regente de la Audiencia cuando se proclamó la Constitución y pasó a ser jefe político superior de la provincia, posteriormente desde agosto de 1821, concentró los poderes gubernativo, militar y de hacienda ${ }^{16}$ por orden virreinal ${ }^{17}$. En abril de 1822 pasaría a desempeñar el

14 Fisher (2000; 2006: 318-321) da por supuesto que la organización en intendencias continuó inalterable hasta 1824 .

15 Pérez Núñez, 2009.

16 Archivo del Ministerio de Relaciones Exteriores del Perú (en adelante AMRREE), Archivo de Límites (en adelante AL), CSG-60, Libro copiador de correspondencia del Gobernador don Pío Tristán con el virrey del Perú, 1819-1824, Pío Tristán acusa recibo de la orden virreinal «de que continúen reunidos el mando militar, político y de hacienda pública en los jefes políticos hasta nueva resolución de las Cortes o hasta que varíe el aspecto de los negocios del mando y sistema de las Provincias», Cusco, 30 de agosto de 1821. En adelante Pío Tristán y Moscoso firmaba como jefe político superior, intendente de hacienda, comandante general de armas de la provincia, ARC, Intendencia, Gobierno, Pedimentos, legajo 242, Orden de Pío Tristán y Moscoso, Cusco, 15 de diciembre de 1821.

17 La medida se ceñía a lo dispuesto en el Art. V, del cap. III, de los Gefes Políticos, en la Instrucción para el gobierno político económico de las provincias de 23 de junio de 1813 para casos excepcionales de amenazas del enemigo o de riesgo de alteraciones del orden público, si bien debería comunicarse los motivos a las Cortes. 
puesto de intendente de hacienda Baltasar Villalonga ${ }^{18}$. En enero de 1823 Tristán fue sustituido por Antonio María Álvarez ${ }^{19}$. En Huamanga Gabriel Herboso ocupó el cargo de jefe político de la provincia durante todo el Trienio Liberal, si bien fue puntualmente sustituido por razones de salud por José de Gálvez, asumiendo el mando militar y las competencias de hacienda al menos desde 1822. Una vez impuesto el absolutismo, sería relevado en mayo de 1824 como intendente por el brigadier José de Montenegro ${ }^{20}$. En resumen, en ninguna de las coyunturas de cambio del absolutismo al liberalismo en 1820-1821 o de retorno al absolutismo en 1824, el virrey removió a los gobernadores regionales. Cambiaron las competencias ${ }^{21}$, que no los hombres, algo que bien pudo ser resultado de que en lo político La Serna priorizó contar con un equipo leal, antes que adecuarlo a los presupuestos ideológicos de cada coyuntura.

El Decreto de las Cortes de 23 de mayo de 1812 reconocía 18 diputaciones provinciales en América, dos de ellas en Perú - Lima y Cusco-, que coincidían con la jurisdicción de las audiencias existentes. La Junta Preparatoria de Elecciones decidió en octubre de 1812 hacer coincidir las demarcaciones electorales con las antiguas intendencias, optándose por un número de representantes en función de los partidos que las componían, con una corrección pertinente en proporción a sus habitantes. En consecuencia, se primó la representación territorial sobre la proporcional al número de ciudadanos. A principios de 1813 se eligieron 49 electores, distribuidos de la siguiente forma: 12 electores por Trujillo, 9 por Tarma, 8 por Lima, 7 por Arequipa y Huamanga, 5 por Huancavelica y 1 por Guayaquil. A fines de marzo de 1813 eligieron la primera Diputación Provincial de Lima. La del Cusco la compondrían 4 representantes por Puno y 3 por Cusco —elegidos por 9 y 11 electores respectivamente-, una proporción que reconocía el mayor peso

18 AMRREE, AL, CSG-60, Pío Tristán acusa recibo de la decisión del virrey de mantener a Villalonga de tesorero y reconocerle el sueldo y prerrogativas del cargo de intendente por nombramiento real, Cusco, 19 de abril de 1822.

19 Ibidem.

20 BNP, MR, D 10006, sesión 12 de mayo de 1824, acuerdo del consistorio relativo a organizar su recibimiento con colgaduras, iluminación, fuegos artificiales, misa de acción de gracias, convite y abrir una suscripción para una bandera. La sesión de 15 de mayo insertaba el oficio del virrey José de La Serna, Yucay, 1 de mayo de 1824, que trasladaba a Herboso a Tarma, y nombraba en su lugar a Montenegro.

21 Los intendentes en las etapas absolutistas concentraron las de gobierno, hacienda, militares y justicia, mientras que los jefes políticos de la provincia solo la gubernativa y, excepcionalmente a causa de la guerra de independencia, las de hacienda y militar, en ningún caso la judicial. 
demográfico de Puno ${ }^{22}$. La instalación efectiva se produjo el 13 de setiembre de $1813^{23}$.

A poco de haber retomado su actividad el 26 de setiembre de 1820, «en los mismos términos y con los propios vocales de que constaba el año de 814» ${ }^{24}$, la Diputación Provincial de Lima quedó inhabilitada, como tantas otras instituciones capitalinas, como consecuencia de la ocupación de la ciudad por San Martín. En Cusco se dilató a tal punto su constitución, que las autoridades locales instaron, en enero de 1821, a que se procediera sin dilación, argumentando que solo entonces se fijarían las atribuciones propias del Ayuntamiento constitucional, puesto que mientras tanto «no puede dar el más pequeño paso» ${ }^{25}$. Es muy posible que la actuación del consistorio hiciera que volviera a instaurarse definitivamente el 26 de febrero de $1821^{26}$, tras varias dificultades para poder reunir a sus miembros — fallecidos o ausentes - No fue el último de los problemas que se hubo de afrontar, como demostraría la intervención decidida del Jefe Político de la provincia, Pío Tristán, exigiendo que se aplicaran los decretos recientes de las Cortes relativos a los mecanismos de elecciones provinciales y $\operatorname{locales}^{27}$ y que los diputados puneños se hicieran presentes en la ciudad ${ }^{28}$.

El 18 de abril de 1822 llegaba al Cusco uno de los cada vez más espaciados correos con noticias oficiales de la Península ${ }^{29}$, en el que se informaba, entre

22 Martínez Riaza, 1992. Peralta, 2005: 86-91.

23 Archivo General de Indias (en adelante AGI), Audiencia de Lima 799, Comunicado de la propia Diputación Provincial, Cusco 26 de julio de 1813.

24 Archivo General de la Nación del Perú (en adelante AGNP), Colección Moreyra, D1.45-1338, Citaciones a las Juntas de la Diputación Provincial, 1813-1820. Oficio del virrey Joaquín de la Pezuela a Francisco Moreyra, Lima, 21 de setiembre de 1820.

25 ARC, LA, Libro 31, Oficios del Ayuntamiento Constitucional del Cusco al Jefe Político, Pío Tristán, Cusco, 12 y 13 de enero de 1821.

26 ARC, Real Audiencia, Administrativo, leg. 176, 1821, Oficio de la Diputación Provincial a la Audiencia, Cusco, 27 de febrero de 1821; Intendencia, Gobierno, Pedimentos, leg. 242, 1814-1824, Oficio de Pío Tristán al Ayuntamiento Constitucional del Cusco, Cusco, 2 de marzo de 1821.

27 AMRREE, AL, CSG - 60, Cusco, Caja 383, Oficio de Pío Tristán al virrey, Cusco, 29 de marzo de 1821, en que ordenaba que en las elecciones de diputados, individuos de la Diputación Provincial y oficios concejiles, se procediera en el territorio de su mando con arreglo al contenido de la Instrucción formada en Guatemala de Orden de la Junta Preparatoria, reimpresa en el Cusco.

28 Ibidem, Oficio de Pío Tristán al virrey, Cusco, 18 de octubre de 1821, consultándole si debían proseguir los anteriores diputados o ser electos de nuevo conforme a su interpretación de la R.O. de 30 de marzo de 1820 y para que ordenara que los diputados provinciales de Puno se presentarán en la ciudad.

29 Ibidem, sendos oficios de Pío Tristán al virrey, Cusco, 18 de abril de 1822. Referencias 
otras muchas cuestiones, que las Cortes habían reconocido el derecho de que se constituyeran diputaciones provinciales propias en cada una de las «Intendencias de provincia» de Ultramar, con sede en su capital ${ }^{30}$. Ello dio lugar a la disolución de la Diputación Provincial del Cusco y a un nuevo proceso de elección de diputados provinciales y de constitución de dichas instituciones en Arequipa, Cusco, Huamanga, Huancavelica y Puno. Si bien su actividad se desarrolló desde al menos junio de 1822 hasta el retorno al absolutismo, y a pesar de ser su gestión clave sobre todo en temas de hacienda y coordinación de los gobiernos locales, carecemos de un balance sobre su política no solo durante el Trienio Liberal, sino también en el primer liberalismo. Anotemos que su papel en el proceso de instauración de ayuntamientos fue determinante, al punto que el propio jefe político superior del Cusco solicitaba el 7 de agosto de 1823 a la diputación provincial de su provincia que le informara de cuántos se habían constituido y los nombres de las autoridades electas ${ }^{31}$.

Peralta ha advertido, con acierto, que seguimos sin tener un balance del número de municipios que se crearon a partir de la aplicación de la Constitución de 1812, ni si hubo continuidad entre los municipios coloniales y los constitucionales $^{32}$. Sin embargo, estudios recientes de Chiaramonti apuntan a que durante el primer liberalismo se habría iniciado un proceso de ruralización de la política, lo que habría condicionado el proceso de construcción del Estado-Nación ${ }^{33}$. Mientras, Paniagua ha enfatizado la importancia que el proceso supuso en lo que ha denominado el inicio del régimen representativo, si bien para el Trienio Liberal solo aporta datos sobre el intento en 1820 del virrey Pezuela en Lima de imponer el consistorio de 1814, evitando nuevas elecciones y un ambiente favorable a los patriotas, junto a referencias puntuales sobre lo acaecido en Huancavelica y Trujillo ${ }^{34}$. Siguiendo la propuesta de Peralta habría que considerar que la extensión de los procedimientos electorales al último confín del Virreinato, permitió una profunda reorganización de las estructuras de poder al interior de pueblos y ciudades y de las relaciones de los ayuntamientos con las altas estructuras de la administración gubernativa ${ }^{35}$. Veamos como se plasmó en Arequipa, Cusco y Huamanga esa nueva realidad.

a la existencia en Cusco de los diarios de debates de las Cortes de 1820 y 1821 en BNL, Manuscritos Colonia (en adelante MC), D 9556.

30 Decreto XIII de 8 de mayo de 1821, Establecimiento de Diputaciones provinciales en las provincias de Ultramar donde no las haya, Colección de los decretos..., 1821, VII: 72-73.

31 AMRREE, AL, Cusco, CSG-60, Caja 383.

32 Peralta, 2005: 69-86.

33 Chiaramonti, 2005: 94-109 y 2007. En términos parecidos para México ver Annino, 1995.

34 Paniagua, 2003: 256-261. Para el caso de Lima: Gamio, 1944. Peralta, 2005: 498.

35 Peralta, 2009: 121. 
La cronología local del regreso a los presupuestos liberales en el sur andino varió sustancialmente, así por ejemplo en el Cusco el Real Decreto de 9 de marzo de 1820, relativo a la jura de la Constitución, fue transmitido a las distintas instituciones por el entonces presidente de la Audiencia e intendente, Pío Tristán, el 2 de octubre de 1820, ordenando su publicación de acuerdo con el ayuntamiento el 11 de dicho mes. En Arequipa se celebró un cabildo abierto el 19 de octubre de 1820, en el que se acordaron las ceremonias de juramentación, fijando para ello el 29 de octubre ${ }^{36}$.

Casi de inmediato se procedió a reinstaurar el Ayuntamiento Constitucional en cada una de las tres ciudades consideradas, sin que nos conste maniobra alguna comparable a la que el virrey Pezuela intentó en Lima para obstaculizarlo. Sin embargo las bases del gobierno local en 1820 presentaban varios matices respecto a los del primer liberalismo. Además de lo establecido en la Constitución de 1812, se habían dado una serie de decretos y reglamentos de cierta trascendencia: Reglamento de las Audiencias y Juzgados de primera instancia de 9 de octubre de 1812; Decreto CLXXIX de 10 de julio de 1812, Reglas sobre la formación de los Ayuntamientos constitucionales; Decreto CCLXIX de 23 de junio de 1813, Instrucción para el gobierno económico politico de las provincias de Ultramar ${ }^{37}$; Decreto CCLXXXI de 11 de agosto de 1813, Varias reglas para gobierno de las Diputaciones provinciales y ayuntamientos de los pueblos. Todos ellos supusieron ciertos cambios en el funcionamiento de las corporaciones locales durante el Trienio. Para su análisis y alcance remitimos a la bibliografía especializada ${ }^{38}$, ciñéndonos en el presente estudio a reflexionar sobre las actuaciones efectivas que hemos podido documentar.

Sí es oportuno introducir un breve apunte relativo a quién ejerció las competencias judiciales durante el Trienio Liberal. El Jefe Político Superior del Perú - antiguo virrey absolutista - y los respectivos de las provincias dejaron de tener intervención alguna en temas de justicia. La Audiencia Nacional del Cusco, tras la desaparición formal de la de Lima, pasó a convertirse en la más alta instancia judicial. En cada uno de los partidos ${ }^{39}$ se nombró un Juez de Le-

36 Un bando de 23 de octubre, difundido con el acompañamiento de tropa y música, convocaba a los vecinos a sumarse a la celebración, adornando las fachadas de las casas de las calles por donde debía transcurrir el previsto «paseo», AMA, LACA, 28.

37 AMRREE, AL, CSG-60, Cusco, Caja 383, Pío Tristán, Jefe Político Superior de la Provincia del Cusco anuncia al virrey en 29 de marzo de 1821 que se dispone a remitir una circular a las autoridades de su distrito con los ejemplares de la Instrucción. Presuponemos que se trataría de la edición limeña de 1820 .

38 Ortego, 2002. Morell, 2003. Martínez Pérez, 1999. Castro, 1979.

39 Las demarcaciones judiciales provinciales fueron objeto de un proyecto elaborado por 
tras, que necesariamente debía ser abogado, mientras que a nivel local y donde se hubiera constituido Ayuntamiento Constitucional, los alcaldes debían actuar de forma obligatoria y al inicio de cualquier causa en actos de conciliación - sin los cuales no se podía iniciar ningún procedimiento judicial—, a los cuales estaban sujetos el conjunto de los habitantes, incluido los aforados militares o eclesiásticos ${ }^{40}$.

\section{APROXIMACIÓN A LAS ELECCIONES LOCALES EN EL PERIODO 1820-1824}

Las tres ciudades fueron de las pocas que gozaron de Cabildo por concesión real y casi desde el inicio de la Colonia. Ciertas elites locales controlaron la institución a través de la obtención de cargos de regidores perpetuos, deviniendo en el verdadero órgano de representación de las oligarquías locales y regionales. Estas proyectaron su influjo sobre el denominado Cercado y, en la práctica, sobre casi todo el espacio regional organizado administrativamente, primero en torno al corregimiento, y desde fines del s. XVIII como Intendencia.

El constitucionalismo doceañista introdujo principios de racionalidad y proporcionalidad en el número de vecinos, como regla básica para fijar los criterios que permitían a un pueblo o núcleo poblado constituirse en Ayuntamiento Constitucional. Y de forma más subrepticia, ello comportó delimitar el área de influencia de las ciudades capitales de provincia a prácticamente el área urbanizada y poco más allá, dando pie a que determinados vecinos vieran en ello una posibilidad de escapar de su control y constituir entidades administrativas propias que les dieran autonomía. Al menos algo así parece haberse dado en el Cusco, cuando las parroquias de San Jerónimo y San Sebastián alegaron en 1821 que superaban las 1.000 almas establecidas por ley, y solicitaron a la Diputación Provincial del Cusco que se les permitiera constituir un ayuntamiento propio para superar las dificultades que comportaba la distancia que les separaba del núcleo urbano del Cusco. De este modo se revertiría una situación en la que solo contaban con alcaldes de pueblo, barrio o cuartel, investidos únicamente de jurisdicción de policía, -léase en la concepción del término en la época, competencias en la gestión de recursos, ornato y orden público- , cuando lo deseable sería que los alcaldes pudieran actuar, como establecía la Constitución, en casos de justicia conciliatoria ${ }^{41}$. Es posible que el

la Diputación Provincial de Lima en 1814, cuyos informes han sido publicados en F. Castillo, L.J. Figallo, L.J. Serrera, 1994: 397-504.

40 Sala i Vila, 2010.

41 Tras elaborar censos de las dos parroquias y estimar que cada cinco individuos equivalían 
mismo proceso se repitiera en Arequipa, donde se creó un ayuntamiento propio en Yanahuara ${ }^{42}$.

No es fácil saber cual fue el sentir de las respectivas ciudades ante la pérdida de influencia en un amplio territorio, aunque cabría pensar que no fue muy de su agrado, pero sobre ello nos movemos más en el terreno de la intuición que de la certeza. Para ello baste apuntar que el ayuntamiento constitucional del Cusco «reiteró» el 23 de enero de 1823 que se le concediera el privilegio conseguido por R.C. de 3 de mayo de 1806 de detentar por turno entre sus miembros la subdelegación del Cercado ${ }^{43}$.

Podríamos apuntar que los ayuntamientos constitucionales se convirtieron en una suerte de espacio institucional en que confluyeron las voluntades de los legisladores constitucionales y las demandas y necesidades de los vecinos, lo que pudo dar lugar a innovaciones $\mathrm{y}$, al mismo tiempo, ciertas continuidades respecto al antiguo Cabildo. La realidad de acercar la gestión a las gentes y a la particularidad de los distintos barrios y espacios urbanos, llevó a que se mantuviera la costumbre de dividir internamente las ciudades en barrios o cuarteles, para cuyo gobierno y administración se nombraron alcaldes o comisarios de barrio, con competencias en asuntos relacionados con el orden público, control de la población y sus desplazamientos, regulación del mercado, distribución de víveres y la recaudación de propios y arbitrios ${ }^{44}$. Arequipa fue dividida en 17 cuarteles $^{45}$, y el Cusco lo sería en 8 barrios, coincidentes más o menos con sus parroquias urbanas. En Huamanga se nombraron en abril de 182315 alcaldes de barrio ${ }^{46}$ y bajo el absolutismo, en junio de 1824 , se dividió en 5 cuarteles ${ }^{47}$. No disponemos de referencias al origen de tal práctica, ni cuál

a un vecino, se fijó el número de electores para cada una de ellas en nueve y la composición de los cargos ediles en un alcalde, cuatro regidores y un procurador síndico. Archivo del Museo Nacional de Arqueología, Antropología e Historia del Perú (en adelante MNAAH), 00696, Expediente sobre la formación de Ayuntamientos de San Sebastián y San Gerónimo. Cusco, 1821.

42 AMA, LAC 30.

43 AMRREE, AL, CSG-60, Cusco, Caja 383.

44 En Huamanga se nombraron bajo el argumento de lograr el «mejor orden, aseo y limpieza de la ciudad». AMA, LACA 30, 1824-1825, sesiones de 8, 12, 15 de enero, 5 de febrero, 2 de octubre de 1824. En el Cusco las instrucciones de los comisarios de barrio llegaron a imprimirse, ARC, LA, Libro 32, sesión de 14 de febrero de 1824.

45 Constituidos en su mayoría por unas seis manzanas de la trama urbana más los núcleos de población del extrarradio como la Pampa de Miraflores, la «otra banda del río» o la Ranchería.

46 La justificación sobre la conveniencia de mantener tal costumbre, su nombramiento y el acuerdo de que se remitiera a la Diputación Provincial para su aprobación en: BNP, MR, D 10006, sesión de 7 de abril de 1823.

47 Ibidem, sesiones de 14 de junio y 5 de julio de 1824, para que se rectificara la división en cuarteles. 
fue la base jurídica de su aplicación durante el periodo constitucional y, sin embargo, todo apunta a que se trató de una de tantas medidas que buscaban resolver las eventualidades cotidianas y mantener normas de convivencia que habían probado su bondad en el tiempo.

El ordenamiento constitucional que surgió de los debates gaditanos basó el poder local en un sistema electivo sustentado en el principio de vecindad y su arraigo parroquial. La condición de vecino se reservaba a los hombres, cabezas de familia, radicados de forma estable en una determinada ciudad y que se ocuparan en labores honrosas. El núcleo que registraba y daba carta de naturaleza a la representación política se circunscribía a la parroquia, espacio no solo de ritualización religiosa, sino también de registro estadístico y de organización de una comunidad de base. En las dos etapas liberales se reunían periódicamente a efectos políticos para delegar su voto en varios electores, quienes a su vez, y junto a los representantes del conjunto de las parroquias, procedían a elegir a los miembros de los ayuntamientos constitucionales y a electores que luego elegirían a diputados provinciales y a Cortes.

Inicialmente se distribuyó el número de electores asignados a cada ciudad en función de los vecinos de cada parroquia, si bien ello se hizo de forma tentativa, ya que no se disponía de censos actualizados. Casi de inmediato se advirtió que no podía posponerse la actualización de los datos estadísticos de la población, por lo que fue preciso elaborar censos, competencia que recaía en las diputaciones provinciales, que a su vez solicitaron a los distintos ayuntamientos los datos actualizados de sus habitantes, lo que generó varios conflictos de competencias entre ambas instituciones ${ }^{48}$.

En las tres ciudades se fijó el número de electores de parroquia en 25. El número de circunscripciones electorales fue disímil, adecuándose más o menos al número de parroquias, con alguna corrección relativa a su área de influencia, cuyo alcance es difícil de comprender, aunque es posible que respondiera al objetivo de lograr un mejor control electoral por determinados grupos de interés. En Arequipa desde las elecciones de 1820 se asignaron 16 y 9 electores respectivamente a dos colegios electorales instalados en los conventos de

48 En el caso del Cusco el ayuntamiento fue inicialmente reticente a elaborar el padrón, excusándose en sus múltiples obligaciones. En algún momento exigió a los párrocos la remisión de un registro actualizado de bautismos y defunciones, lo que mereció la reprobación del jefe político de la provincia, Pío Tristán, quien consideraba que ello era competencia de alcaldes y regidores, ARC, LA, Libro 31, Oficios a los párrocos de las ocho parroquias del Cusco de 3 de abril y 26 de mayo de 1821, a Pío Tristán de 21 de julio de 1821, en cumplimiento del art. 2. ${ }^{\circ}$ de la Ley de 23 de junio de 1813. Ibidem, Libro 32, sesiones de 25 de enero, 1, 22 de febrero, 8,22 de marzo, 5 de abril y 20 de diciembre de 1823 . 
Santo Domingo y San Francisco, correspondientes a las parroquias de Santiago y Santa Marta ${ }^{49}$. En el Cusco, los electores se distribuyeron proporcionalmente al vecindario estimado en cada una de las ocho parroquias ${ }^{50}$. Por último en Huamanga, aunque desconocemos la distribución concreta, sabemos que se hizo en base a tres parroquias, Sagrario, Santa Ana y Santa Magdalena. A la del Sagrario se le anexó San Juan Bautista, extendiendo el área de influencia de Santa Ana hasta la Chiara ${ }^{51}$.

Santa Ana y Santa Magdalena eran las parroquias huamanguinas de indios, anan y urin respectivamente. El hecho de que se extendiera la circunscripción electoral de Santa Ana hasta la Chiara, un núcleo relativamente lejano de la ciudad, de poblamiento disperso y dominado por haciendas ganaderas, o la inclusión de los habitantes —indios y mestizos - de San Juan Bautista en una parroquia de españoles como el Sagrario, pudo obedecer al deseo de relativizar el peso específico de la población india urbana, un objetivo que se logró puesto que no hay constancia documental de su presencia entre los cargos electos. En Arequipa la parroquia de indios era Santa Marta, sobre la cual disponemos de referencia documental suficiente de los vecinos sufragantes en diciembre de 1821. Del total de 112 vecinos registrados, solo nueve podrían ser identificados por su apellido tentativamente como tales, y entre los electores de parroquia solo dos lo serían. En Cusco solo hemos podido documentar a dos indios, Ilario Yanquirimachi (sic) y Jorge Puma Inga, como electores, ambos en la parroquia de Piezas ${ }^{52}$. Ello indicaría o bien una abstención generalizada de los indios de dichas parroquias o dificultades para obtener la preceptiva papeleta de vecino para ejercer el derecho a voto, que debía otorgarles el párroco respectivo.

Los legisladores proyectaron un Ayuntamiento Constitucional entendido como una institución nueva y electiva, sin embargo no se derogaron los principios de organización urbana colonial, que tendía a segregarse internamente en espacios asignados a distintos grupos étnicos, cada uno con su propia parroquia. Ello comportó que se crearan ayuntamientos multiétnicos, al eliminarse los cabildos diferenciados de españoles e indios, al mismo tiempo que se man-

49 AMA, LACA, LPE01 y LP02, 1813-31/3, Libros de Junta de Ciudadanos de Electores de Santo Domingo y San Francisco.

${ }^{50}$ La distribución de electores fue de 6 por la Matriz de Españoles, 5 por la de Piezas, 5 por la de San Pedro, 2 por la de Belén, 1 por la de Santa Ana, 2 por la de Santiago, 1 por la de San Cristóbal y 3 por la de San Blas, ARC, Intendencia, Gobierno, Pedimentos, leg. 242, 1814-1824, Orden de Pío Tristán y Moscoso, Jefe Político Superior, Intendente de Hacienda, Comandante General de Armas de la Provincia, Cusco, 15 de diciembre de 1821.

51 BNP, MR, D 10006, sesión de 27 de diciembre de 1822.

52 ARC, Libro 32, acta electoral de 23 de diciembre de 1823. 
tenía la parroquia como base de definición de la circunscripción electoral. Su resultado fue que, por simple correlación de fuerzas, los indios quedaron relegados en las elecciones, al ser las parroquias de blancos y mestizos superiores en número o como consecuencia de políticas, más o menos subrepticias, que, como hemos apuntado, difuminaron o eliminaron pura y llanamente su presencia entre los electores o cargos ediles. Algo distinto ocurrió en los pueblos constituidos en torno a una única parroquia, en los que por su corto vecindario no había una que fuera específica de españoles. Allí hemos detectado que la presencia indígena entre electores de parroquia y cargos electos fue significativa, como muestran los casos de Azángaro, Coasa y Asillo en Puno, o el de San Jerónimo en Cusco, que hemos expuesto anteriormente, donde fue electo en las primeras elecciones de 1821 como alcalde el capitán Mariano Tisoc Saritupa ${ }^{53}$.

No solo el nuevo ordenamiento constitucional, sino también la cultura política de corte liberal, impusieron un cambio sustancial en la representatividad y escenificación pública de las diferencias étnicas. Quizás la metáfora de todo ello podemos situarla en el Cusco, donde desde tiempo inmemorial el cabildo de indios, representado por su alférez real y los 24 electores, desfilaba la víspera y festividad de Santiago Apóstol, patrón de Estaña, portando el Estandarte Real ${ }^{54}$. Si la costumbre había perdurado a lo largo del periodo colonial, se vería truncada en las dos etapas liberales. Como afirmaba textualmente Antonio Martínez, subdelegado del Cercado en junio de 1824, su desfile cívico se había efectuado anualmente «a excepción de las épocas constitucionales que han interrumpido, igualmente que al Exmo. Cabildo de españoles» ${ }^{55}$. El liberalismo casaba mal con el mantenimiento de las divisiones estamentales, y ello fue percibido a la cabalidad por la nobleza indígena en todo el Virreinato, cuando constató que este les situaba en igualdad de derechos al común de los indios, aboliendo de forma implícita el gobierno de tipo señorial que presuponía el cacicazgo, pero también cualquier preeminencia social basada en principios estamentales o la propia capacidad de organizarse en cabildos y disponer de alcaldes étnicos ${ }^{56}$.

53 MNAAH, s. XIX (D), 001692, acta de elección de ayuntamiento y alcalde del pueblo Azángaro, 9 de diciembre de 1821; 001645, Ibidem, Santa Bárbara de Coasa, 15 de diciembre de 1821; 001646, Ibidem, Asillo, 25 de diciembre de 1821; 00696, Ibidem, San Jerónimo, 9 de diciembre de 1821 .

54 Amado, 2002. Garrett, 2009. Sala i Vila, 1990.

55 ARC, Intendencia, Gobierno Virreynal, 160, 1823-1824, Informe del Subdelegado del Cercado, Cusco, 10 de junio de 1824, inserto en el Expediente sobre que se continúe en esta capital el paseo del Pendón Real en las Vísperas y días del Apóstol Señor Santiago.

56 Sala i Vila, 1992. 
Los ayuntamientos constitucionales de Arequipa, Cusco y Huamanga debían estar integrados, en su calidad de capitales de provincias y según el artículo 315, capítulo $1 .^{\circ}$, título 6 de la Constitución Política de la Monarquía y el Decreto de 23 de mayo de 1812, por 2 alcaldes, 12 regidores y 2 procuradores $^{57}$. Dicha estructura, junto al número de electores, se mantuvo en el Cusco a pesar de la pérdida de las parroquias de San Sebastián y San Jerónimo, cuando estas pasaron a constituirse como ayuntamientos autónomos ${ }^{58}$. Según las fuentes de que disponemos, en diciembre de 1822 se eligieron 2 alcaldes, 6 regidores y el $2 .^{\circ}$ síndico ${ }^{59}$.

En 1823 las autoridades aplicaron el Decreto de 23 de marzo de 1821 que modificaba el número de miembros de cada ayuntamiento según su proporción de vecinos. En consecuencia el jefe político de la provincia del Cusco, Antonio María Álvarez, elevó a tres el número de alcaldes elegibles, pero mantuvo el número de regidores o procuradores síndicos, en tanto que se elaborara un padrón de población que permitiera fijar la composición de la corporación acorde con la nueva legislación ${ }^{60}$. No hay constancia de que en Arequipa o Huamanga ${ }^{61}$ se produjera modificación alguna en consonancia con dicho cambio normativo.

Los ayuntamientos constitucionales, al quebrar los tradicionales mecanismos de control en propiedad de los cargos concejiles, supusieron una oportunidad para que determinados sectores urbanos accedieran espacios de poder local. Evaluar si ello fue o no una realidad es especialmente complejo para los casos que nos ocupan, ya que no contamos con estudios previos sobre la composición del cabildo colonial que nos permitan calibrar el proceso y estimar

57 ARC, Intendencia, Gobierno, Pedimentos, leg. 242, 1814-1824, Orden de Pío Tristán, Cusco, 15 diciembre de 1821.

58 ARC, LA, Libro 32, actas electorales de 29 de diciembre de 1822 y de 23 de diciembre de 1823.

59 Renovándose cada año solo la mitad de los regidores y síndicos, electos por un periodo de dos años.

60 Si los pueblos tenían entre 4.000 y 10.000 vecinos, sus respectivos ayuntamientos se compondrían de 3 alcaldes, 12 regidores y 2 procuradores síndicos, elegidos por 19 electores de sus respectivas parroquias, Decreto $I V$ de 23 de marzo de 1821. Aclaraciones de la ley de 23 de mayo de 1812 sobre formación de Ayuntamientos Constitucionales, Colección de los decretos..., 1822, VIII: 13. Excepcionalmente se eligió un séptimo regidor, al aceptarse la renuncia de Rafael Urbina por motivos de salud, ARC, LA, Libro 32, acta electoral de 23 de diciembre de 1823.

61 En Huamanga, Gabriel Herboso, jefe político y militar, ordenó en diciembre de 1822 la elección de dos alcaldes, 6 regidores y 2 síndicos. Se renovaron los dos síndicos a causa de que José Matías León había sido trasladado a un puesto judicial en Cochabamba, BNP, MR, D 10006. 
los cambios y continuidades que se sucedieron. Tampoco hemos podido, dada la fragmentación de la documentación que se ha conservado, reconstruir el conjunto de los electores de parroquia o de los miembros de las corporaciones locales.

Poco sabemos de los 88 electores de las parroquias de Santiago ${ }^{62}$ y Santa Marta $^{63}$ de Arequipa, que fueron sufragados e intervinieron en los cuatro procesos de elecciones que se sucedieron entre 1820 y 1824 . Entre los electores de parroquia destaca la ausencia de los miembros de la elite económica o burocrática de la ciudad, lo cual podría ser un indicador, que solo podrá demostrar futuras investigaciones, de la presencia significativa de grupos meritocráticos vinculados a profesiones liberales, al artesanado y al pequeño y mediano comercio urbano ${ }^{64}$.

En el Cusco, entre los electores de parroquias de $1822^{65}$ y $1823^{66}$, destaca la proporción de sacerdotes ${ }^{67}$ y comerciantes ${ }^{68}$, la menor de hacendados como

62 Los electores de la parroquia de Santiago fueron Manuel Amat y León, Estanislao Araníbar, Mariano Areanasas, Juan de Dios Bueno, Antonino Corvacho, José Dávila, Fernando Fierro, Gervasio Lastarria, Lucas Lovaina, Francisco Nieves, Lorenzo Quadros, Pío Quiroz, Manuel Tirado, Manuel de Ureta, Francisco Valdez de Velasco y Alexandro Valencia en 1820; Estanislao Araníbar, Francisco Arrospide, Juan de Dios Bueno, José Calle, Antonio Corbacho, Rafael Chocano, José Dávila, Andrés Eguiluz, Pedro Masias, Ignacio Noboa, Teodoro Pastor, Diego Pover, Federico Recavaren, Pío Tirao, Mariano Ugarte y Llosa y Francisco Vera en 1821; José Abalos, Bernardino Cáceres, Faustino Delgado, Antonio Ferrandis, Eugenio Fierro, Melchor Guerola y Cano, José María Laxana, Rudesindo López, Miguel Oviedo, Fernando Rivero, Juan Fermín Salas, José Salazar, Casimiro Salazar, Mariano Salguero, José Teodoro Villanueva y Juan Nepoducemo Zegarra en 1823 y Mariano Avenara, Andrés Bedoya, Francisco Bermedo, Evaristo Carvajal, Antonio Corbacho, Jacinto de la Cruz, Juan Corzo y Salazar, Juan Bautista Garate, Semt. ${ }^{\circ}$ García, Santiago Jamero, Rudesindo López, Pedro Domingo Masias, Miguel Oviedo, Juan Manuel Somocurso, Pedro Tirado y Atanasio Truxillo en 1824, AMA, LPE01.

63 Los electores de parroquia de Santa Marta fueron Alberto Anco, Luis Cerna, Miguel García, Rafael Guillen, Manuel Mendoza, José Romero, Toribio Prado, Mariano Solorzano y Manuel Zenteno en 1820; José Ariscayn, Fernando Fierro, Santiago Gamero, Rafael Guillen, Lucas Loayza, José Romero, Luis Serna, Juan José Zegarra y Manuel Zenteno en 1821; Mariano Baldivia, Manuel y Mariano Bargas, Jacinto de la Cruz, Pedro Oricain, Julián Rivera, Antonio Rivera, Pablo Rondon y Francisco Luis de Zoza en 1823; y José Bedoya Laguna, Fermín Canseco, Miguel García, Manuel Calderón Chura, Manuel Calderón Chuquicallata, Cleto López, Mariano Salguero, Luis Serna y Manuel Solar en 1824, AMA, LPE02.

64 Diez de ellos repitieron en algún periodo como electores y cinco serían alcaldes durante el Trienio Liberal — Juan Bautista Gárate, Pedro Domingo Masías, Ignacio Novoa y Arteta - o en la temprana república - Juan Corzo y Salazar, Manuel Ureta-.

65 Mariano Villafuerte, Juan José Olañeta, Benito Espinosa, José Maruri de la Cuba, Felipe Torres y Juan Alegría por la Matriz; Jerónimo Velasco, Bartolomé Gallegos, Juan Gualberto Torres, Felipe Obando y Francisco Aramburu por la de Piezas; Norberto Alosilla, Rafael Silva, 
Manuel Luna o Evaristo Yabar. Además, se encuentra alguna referencia a personajes con grados militares o de milicias ${ }^{69}$. En algún caso los electores terminaron siendo electos, como Mariano Villafuerte o Juan Alegría, alcalde y regidor respectivamente en 1823, o Juan José Olañeta diputado a Cortes durante el Trienio Liberal ${ }^{70}$.

Las elecciones locales no estuvieron exentas de incidentes, y en ocasiones debieron repetirse de forma puntual al constatarse a posteriori que ciertos cargos electos no cumplían alguna de las exigencias establecidas en la legislación vigente, como la vecindad. En las elecciones de 1823 en el Cusco se cuestionó la vecindad del alcalde de tercer voto y de uno de los regidores, con consecuencias disímiles. El subdelegado de Paruro, Juan Pinto y Guerra, pidió la anulación de la elección del alcalde de 3 . ${ }^{\text {r }}$ voto, Jacinto Ccama, porque previamente había sido electo alcalde constitucional de Yaurisque, en Paruro, donde tenía fijada su residencia. Tras debatir el caso, los electores decidieron que debía tomar posesión en el Cusco, porque cualquier elección para un cargo en la capital debía ser preferente a la que se había hecho en Yaurisque y por el hecho de estar casado con una vecina del $\mathrm{Cusco}^{71}$. Lorenzo Sugarciaga no tomó

Valeriano Flores, Esteban Peña y Mariano Vargas por la de San Pedro; Toribio Carrasco y Antonio Martínez por la de Belén; Evaristo Yabar y Melchor Marmarillo por la de Santiago; Tomas Obando por la de Santa Ana; Miguel Aranívar, Vicente Alarcón y Mariano Aramendi por la de San Blas y Bartolomé Alosilla por la de San Cristóbal. ARC, Libro 32, acta electoral de 29 de diciembre de 1822 .

66 Julián Llave, José Cáceres, Antonio Otasu, Martín Sambrano, Julián Cáceres y José Gaspar Gabancho por la Matriz; Gerónimo Velasco, Santiago Terno, Felipe Obando, Ilario Yanquirimachi y Jorge Puma Inga por la de Piezas; Mariano Pimentel, Agustín Rosel, Francisco Ochoa, Rafael Silva y Laurencio Vejar por la de San Pedro; José Mariano Palomino y José Felipe Loayza por la de Belén; Evaristo Cortes de Yabar y Mariano Chaparro por la de Santiago y Juan Mendoza por la de Santa Ana. ARC, Libro 32, acta electoral de 23 de diciembre de 1823.

67 Cinco en 1822 - José Maruri de la Cuba, Felipe Torres, Francisco Aramburu, Mariano Vargas cura de Lamay y Toribio Carrasco cura de Belén-y tres en 1823 - Martín Sambrano, Julián Cáceres, José Gaspar Gabancho-.

68 En 1822 lo eran Juan José Olañeta, Norberto y Bartolomé Alosilla, Juan Alegría, Jerónimo Velasco, Bartolomé Gallegos, Rafael Silva, Esteban Peña y en 1823 Antonio Otasu, Martín Zambrano, Gerónimo Velasco, Felipe Obando, Rafael Silva, José Felipe Loayza, identificados a partir de los empréstitos exigidos a comerciantes cusqueños en 1823 y 1824, CDIP, XXII, Gobierno virreinal del Cuzco, 3: 91-94, 116-117, 120-122.

69 En 1822 el coronel Mariano Villafuerte, capitán Juan José Olañeta, teniente coronel Norberto Alosilla y el teniente Juan Alegría; en 1823 el coronel Julián Llave.

70 Era además administrador del obraje Picuichuro, propiedad de su suegro Sebastián José de Ocampo, Escandell, 1997: 132. Entre los electores también estuvo José Cáceres, secretario de la Diputación Provincial.

71 ARC, LA, Libro 32, acta electoral de 23 de diciembre de 1823. Fue incluido como con- 
posesión de regidor tras manifestar de motu propio que no era vecino, aportando como prueba el pasaporte firmado por el virrey Pezuela ${ }^{72}$. En Huamanga se tuvo que repetir la elección del alcalde para el ejercicio de 1824, al constatarse que el electo marqués de Mozobamba del Pozo era en realidad vecino de la doctrina de Ocobamba ${ }^{73}$.

La ingerencia del jefe político superior de la provincia en los procesos electorales fue evidente en alguna ocasión, como en el caso del Cusco, donde Antonio María Álvarez anuló el 8 de enero de 1823 las elecciones del alcalde de $1 .^{\mathrm{a}}$ elección, de los regidores $11 .^{\circ}$ y $12 .^{\circ}$ y del síndico $2 .^{\circ}$, por motivos legales que no se explicitan en la documentación, procediéndose a una nueva elección ${ }^{74}$. Hubo otras convocatorias de elecciones parciales. Así en Huamanga, el regidor electo Vicente Ruiz fue eximido por el virrey de tomar posesión en 1823 por causas justificadas, lo que dio pie a convocar una nueva elección el 24 de febrero de 1823, en la que fue sustituido por Pedro José Bendezu ${ }^{75}$. Del mismo modo hubo varias renuncias, a pesar de lo que dictaba la legislación, como las del alcalde de $2 .^{\circ}$ voto de 1823 , Norberto Torres de la Cámara, que pidió una sustitución temporal y, poco después, renunció definitivamente a causa de la enfermedad de su esposa ${ }^{76}$; la del regidor conde de Villaminaya, que no llegó a tomar posesión de regidor en 1824 aduciendo razones de salud ${ }^{77}$; la petición de permisos temporales, como la del alcalde Juan José Miota en enero de 1823 para ausentarse al valle del Urubamba a recaudar diezmos y administrar sus haciendas ${ }^{78}$, o la del síndico Dionisio Dávila en marzo de 1824, para desplazarse al partido de Tinta donde debía resolver asuntos familiares ${ }^{79}$.

En el estado actual de nuestros conocimientos no nos es posible concluir en qué medida el sistema representativo modificó la composición social de los alcaldes y regidores respecto al anterior cabildo perpetuo. Para el Cusco no disponemos de la relación completa de los alcaldes, ni de la de regidores para las tres ciudades estudiadas. Tampoco estamos en condiciones de ofrecer una

tribuyente en Yaurisque en el préstamo forzoso de 40.000 pesos exigido en marzo de 1823 , CDIP, XXII, Gobierno virreinal del Cuzco, 3: 102.

72 Ibidem, acta electoral de 30 de diciembre de 1823.

73 BNP, MR, D 10006, sesión de 12 de enero de 1824.

74 ARC, LA, Libro 32, acta electoral de 8 de enero de 1823.

75 Ibidem, acta electoral de 23 de diciembre de 1822, sesiones de 21 y 24 de febrero de 1823.

76 Ibidem, sesiones de 13 de setiembre y 19 de octubre de 1823 .

77 Ibidem, acta electoral de 30 de diciembre de 1823.

78 Ibidem, sesión de 17 de enero de 1824.

79 Ibidem, sesión de 6 de marzo de 1824. 
prosopografía de los alcaldes, dada la parquedad de los datos que ofrecen las fuentes consultadas y el disímil grado de desarrollo de las respectivas historiografías regionales. Con todo proponemos un esbozo tentativo. El cuadro n. ${ }^{\circ} 1$ incluye los nombres de los alcaldes que hemos podido documentar y en él se consignan correlativamente el de primer y segundo voto.

\section{Cuadro n. ${ }^{\circ}$ 1. Alcaldes de Arequipa, Cusco y Huamanga DURANTE EL TRIENIO LIBERAL}

\begin{tabular}{|c|c|c|c|}
\hline & Arequipa & Cusco & Huamanga \\
\hline 1820 & $\begin{array}{l}\text { Bruno Llosa Araníbar } \\
\text { Luis Gamio }\end{array}$ & & Raymundo Gómez de Segura \\
\hline 1821 & $\begin{array}{l}\text { Ignacio Novoa y Arteta } \\
\text { Pedro Domingo Masias y Ji- } \\
\text { ménez }\end{array}$ & & $\begin{array}{l}\text { Miguel de Yriarte } \\
\text { José Soto }\end{array}$ \\
\hline 1822 & $\begin{array}{l}\text { Juan Bautista Arrospide } \\
\text { Juan Mariano Cossío y Urbi- } \\
\text { caín }\end{array}$ & $\begin{array}{l}\text { Manuel Torres y Marco } \\
\text { Mariano de Villafuerte }\end{array}$ & $\begin{array}{l}\text { José de Gálvez } \\
\text { Raymundo Gómez de Arriaran }\end{array}$ \\
\hline 1823 & $\begin{array}{l}\text { José Mariano Menaut } \\
\text { Mariano Basilio de la Fuente y } \\
\text { Bustamante }\end{array}$ & $\begin{array}{l}\text { Mariano Villafuerte } \\
\text { Norberto Torres de la Cámara }\end{array}$ & $\begin{array}{l}\text { José Carrasco } \\
\text { Marcos Pantoja }\end{array}$ \\
\hline 1824 & $\begin{array}{l}\text { Pedro Domingo Masías } \\
\text { Juan Bautista Gárate }\end{array}$ & $\begin{array}{l}\text { Julián Llave } \\
\text { Juan José Miota } \\
\text { Jacinto Ccama }\end{array}$ & $\begin{array}{l}\text { José Antonio López del Romar } \\
\text { José Luis de Ochoa }\end{array}$ \\
\hline
\end{tabular}

En Arequipa pudiera presuponerse que hubo una cierta continuidad entre las elites que controlaron el cabildo y el ayuntamiento constitucional, al menos ello podría concluirse del hecho que ciertos alcaldes lo fueran en una y otra institución absolutista y liberal: Bruno de la Llosa y Zegarra (1804 y 1820) ${ }^{80}$; Juan Mariano Cossío y Urbicaín (1816, 1822 y 1827); Juan Mariano Menaut (1799, 1800, 1815 y 1823). Otros eran hijos de antiguos alcaldes del cabildo: Pedro Domingo Masías y Jiménez $(1813,1821)$ y Luis Gamio y Araníbar eran hijo y yerno de Pedro Domingo Masías $(1805,1806)$; Mariano Basilio de la Fuente (1823) de Francisco de la Fuente y Loayza (1779, 1797, 1798 y 1812). O de autoridades regionales: José Mariano Menaut de Francisco Menaut y Theres, corregidor de Collaguas y Caylloma. No encontramos a miembros de las familias poseedoras de las grandes fortunas de la época - Goyeneche, Tristán, Cotera...-, más bien parece aflorar entre los electores de parroquia y

80 Entre paréntesis se da la referencia de los años en que fueron alcaldes, fuera de cabildo, de ayuntamiento constitucional o municipalidad republicana. 
ciertas autoridades del ayuntamiento una mesocracia urbana, que trascendió de forma destacada en la república. Una de las hijas de Masías y Jiménez se casó con el que sería presidente, Remigio Morales Bermudez; dos de los hijos de Gamio y Araníbar fueron rectores de la Universidad de San Agustín, y un hermano suyo alcalde en 1828; Pedro Ignacio Novoa y Benavides, hijo de Ignacio Novoa y Arteta (1821) natural de Guayaquil y abogado, fue diputado en 1851-1853 y ministro de Hacienda en 1863-1864; Cossío y Urbicaín fue prefecto de Arequipa y diputado ${ }^{81}$.

En Cusco Juan José Miota (1824) era hacendado y Jacinto Ccama (1824) dueño del obraje Taray ${ }^{82}$. En Huamanga, los alcaldes de 1821, Miguel Iriarte y José Soto eran comerciantes ${ }^{83}$. Poco o nada sabemos de los restantes, aunque algunos pudieron ser hacendados como José Carrasco, capitán de milicias de la villa de Huanta, o el marqués de Mozobamba del Pozo, cuya heredera Brianda Cabrera era dueña de la hacienda Tartaria ${ }^{84}$.

\section{BALANCE DE LAS POLÍTICAS DE LOS AYUNTAMIENTOS CONSTITUCIONALES}

La legislación liberal otorgó un conjunto amplio de competencias a los ayuntamientos constitucionales: cuidado del ornato y orden público, urbanismo, alumbrado ${ }^{85}$, mantenimiento de canales y acequias, provisión de agua, refacción de caminos y puentes, mercados, higiene y sanidad - limpieza urbana, cementerios, tutela de hospitales y establecimientos de beneficencia, vacunas-, fiestas cívicas y religiosas, educación, fomento de la economía, hacienda y asuntos militares — cupos, empréstitos y levas—86. Sin ánimo de exhaustividad, aportamos algunos ejemplos de la aplicación práctica de tales políticas, destacando aquellos casos que presentaron ciertas particularidades.

A medio camino entre velar por la higiene y la necesidad de ordenar el espacio público cabe interpretar la política del ayuntamiento cusqueño de trasla-

81 Solo en el caso de Francisco Menaut tenemos datos de que fuera hacendado. Martínez, 1946. Brown, 2008. Chambers, 2003.

82 Escandell, 1997: 268.

83 Miguel Iriarte era diputado de comercio y el mayor contribuyente con 5.000 pesos en el empréstito forzoso de fines de 1821, ARAy, Intendencia, Asuntos Administrativos, 42, cuaderno 58. Expediente sobre préstamos a la Hacienda Nacional, 1820-1821.

84 ARAy, Asuntos Administrativos, 40, C. n. ${ }^{\circ}$ 42, Plan de haciendas del partido de Guamanga, 1823.

${ }_{85}$ Costeado por ejemplo en el Cusco por una tasa específica señalada a los comercios.

86 Instrucción para el gobierno económico-político de las provincias, 23 de junio de 1813. Capítulo I. De las obligaciones de los Ayuntamientos. 
dar a las vendedoras de la plaza de San Francisco a la plazuela de San Antonio o al portal de Panes, porque se consideró su emplazamiento inicial carente de limpieza, decencia y la plaza «muy embarazada con la concurrencia de todos» ${ }^{87}$; o su intento de mudar a los arrabales las chicherías que invadían las principales calles, lo que se adjetivaba de «ser indecoroso al honor y policía de esta capital»; o la clausura y venta al mejor postor del callejón existente entre el convento de San Agustín y la casa de Andrés Villamil por ser «inútil y aún perjudicial a la ciudad ${ }^{88}$.

En tiempos de guerra se promovieron especiales manifestaciones cívicas para celebrar las victorias militares o rendir homenaje a los oficiales destacados, además de demostraciones públicas en honor de las altas autoridades virreinales que pasaron a residir en una zona que les había sido ajena tradicionalmente. En el Cusco se festejó en 1822 la llegada del virrey a la nueva sede de gobierno con corridas de toros, cuyo importe superó los 2.500 pesos $^{89}$. En Huamanga se decidió organizar el primero de noviembre de 1823 una noche de refresco en honor de los generales Canterac y Valdés con motivo de «la campaña que con tanta gloria acaban de concluir» y regalar al primero un sable de oro para celebrar sus victorias en Torata y Moquegua ${ }^{90}$.

En asuntos religiosos, los ayuntamientos constitucionales buscaron establecer relaciones de igualdad con los cabildos eclesiásticos, sobre todo en temas de protocolo, en un contexto político liberal poco proclive a mantener formas de religiosidad barroca y tendente a ejercer desde el poder político el control y reformar las fiestas y ceremonias religiosas tradicionales. En tal sentido

87 ARC, LA, Libro 32, sesiones de 24 de enero y de 28 de febrero de 1824.

88 Ibidem, sesión de 5 de febrero de 1824.

89 De los cuales 1.300 pesos eran producto del remate de la plaza y 1.200 contribución de los subdelegados de Quispicanchis, Paruro, Urubamba, Calca y Chumbivilcas. Como los dueños de los balcones se negaron a contribuir con un tercio de sus beneficios de arrendarlos a la afición taurina, el ayuntamiento protestó recordando que si bien la propiedad era un derecho sagrado, los principios de economía política que habían guiado al ayuntamiento se situaban dentro del debate siguiente: «es muy común entre los economistas la cuestión de si las Autoridades sociales pueden limitar el uso del derecho de propiedad y ninguno duda que pueden hacerlo siempre que su uso inmoderado choque a los derechos de los demás». Recordaban como en París, ante la carestía de alimentos luego de un duro invierno, se optó por confiscar los alimentos acaparados por unos pocos y venderlos entre la población. Y en consecuencia algo, tan aparentemente banal como unas corridas de toros se convirtieron en un asunto que permitía asentar el principio del bien público sobre el interés privado, ARC, LA, Libro 31, Oficios a Pio Tristán de 22 de mayo, 11, 20 y 22 de junio de 1822; oficio al virrey de 8 de junio de 1822 .

90 Se financiaría con aportaciones más o menos voluntarias de las autoridades municipales, de los vocales de la diputación provincial y del ramo de mojonazgo, BNP, MR, D 10006 y ARC, LA, Libro 32 y 33, sesiones de 28 de junio y 13 de diciembre de 1823. 
se tendió a reducir los costos de determinadas fiestas, que gravaban sobre el erario municipal, lo que comportó enfrentamientos con los eclesiásticos encargados de tales celebraciones, como en el caso del Cusco donde se regatearon constantemente las aportaciones a determinadas fiestas organizadas por parroquias y conventos ${ }^{91}$. Pero, sobre todo, se buscó imponer una nueva estética religiosa, como mostró la exigencia del jefe político de la provincia del Cusco para que el ayuntamiento pusiera fin a la tradición de construir altares efímeros y nombrar diputados para organizar la festividad del Corpus, lo que llevó a reducir todo el aparato tradicional a solo un dosel y cuatro candeleros en 182392. O cuando el propio ayuntamiento exigió a principios de 1824 que se retiraran las imágenes que se veneraban en plena calle de La Merced y en la plaza de San Francisco, exigiendo a sus devotos que las trasladaran a las iglesias que quisieran, "por ser indecorosos al culto de los santos que sus imágenes se hallen en lugares de esta publicidad $\iota^{93}$.

Los consistorios intervinieron en la difusión de las ideas y del conocimiento de forma muy diversa y trascendente. Las nuevas tendencias en la gestión y difusión de noticias y pareceres, llevó a que el Ayuntamiento del Cusco se planteara y aprobara una partida para adquirir una imprenta ${ }^{94}$. Fueron activos en lo relativo a la educación primaria, pero sobre todo en promover la educación superior.

El síndico personero de Huamanga, Cayetano Medina y Urquizu, denunció el 14 de enero de 1823 que los estudiantes oyentes, denominados capistas, no eran aceptados en la Universidad Nacional y Pontificia de San Cristóbal, lo que a su parecer contravenía las leyes de la Nación y la Constitución política y los principios que las inspiraban de promover la justicia y la equidad. De resultas, se abrió un expediente en el que tuvieron voz los eclesiásticos denunciados, la diputación provincial por sus competencias en los planes de estudios y la enseñanza pública, el jefe político de la provincia y la audiencia nacional del $\mathrm{Cusco}^{95}$. La diputación provincial apuntaba que de marginarse a los estu-

91 Fricciones relativas a la fiesta de Nuestra Señora de Nieva con el convento de la Merced, ARC, LA, Libro 32, sesión de 24 de enero de 1824.

92 Ibidem, sesiones de 22 de febrero y 10 de mayo de 1823. Un estudio de la fiesta colonial del Corpus en el Cusco en Dean, 2002.

93 Ibidem, sesión de 14 de febrero de 1824.

94 ARC, LA, Libro 31, Oficio del Ayuntamiento Constitucional del Cusco a Galingo y Torres, Cusco, 4 de abril de 1821.

95 Según Manuel Renteros, catedrático de vísperas de Teología y rector del Seminario Nacional y Conciliar, solo podían asistir a las clases quienes costeaban sus estudios, ya que según él, seguía vigente lo dispuesto en las Leyes de Indias, al no haberse constituido aún la Dirección General de Estudios prevista en el título 9, capítulo único, artículo 369 de la Constitución, 
diantes oyentes, se establecería un «monopolio de luces», perjudicando a aquellos que no podían acceder a una beca o costearse la plaza de colegial y remitían al decreto de Cortes sobre enseñanza, cuyo artículo 1 . $^{\circ}$ establecía que «toda enseñanza costeada por el Estado o por cualesquiera corporaciones con autorización del gobierno debe ser pública y uniforme». José de Herboso, jefe político de la provincia, no reconocía derecho alguno a los capistas, y, en aras de la utilidad del vecindario, defendía los «estudios de las artes útiles y necesarias, dejando la rutina de las ciencias especulativas y eclesiásticas». El fiscal de la audiencia del Cusco, Joseph Miguel Mujica ${ }^{96}$, redactó un dictamen con tres propuestas: la restitución de los derechos de oyentes a los $\operatorname{capistas}^{97}$, la destitución del catedrático y director del seminario, Manuel Renteros, y la visita y reforma del seminario acorde con lo establecido en las R.O. de 4 de mayo y 7 de julio de 1815. El virrey La Serna se mostraría de acuerdo con el dictamen fiscal el 30 de mayo de 1823, con lo que validaba la política del ayuntamiento constitucional de Huamanga de extender la educación superior en lo posible al conjunto de vecinos, tuvieran o no medios para costearse sus estudios ${ }^{98}$

En Arequipa el ayuntamiento constitucional se implicó decididamente en la creación y financiación de la Academia Lauretana de Ciencias y Artes. A iniciativa del síndico procurador Dr. D. Evaristo Gómez Sánchez, el virrey La Serna aprobó sus constituciones ${ }^{99}$, celebrándose su puesta en funcionamiento el 10 de diciembre de 1821, día de su patrona la virgen de Loreto. Tal institución sentó las bases de la educación superior pública y laica en la ciudad, sustituyendo la hegemonía religiosa en los estudios superiores, ejercida por el Se-

ni haberse abolido el patronazgo. El gobernador del obispado negó todo derecho a la intromisión de las autoridades civiles en materias sujetas, según él, a la jurisdicción eclesiástica.

96 Había sido diputado por Huamanga a las Cortes de Cádiz en la legislatura 1813-1814.

97 Excluía de todo derecho a los no ciudadanos — «nacimiento adulterino, sacrílego, incestuoso»- y se remitía a la consulta del diputado por Guatemala Larranza a las Cortes y a la R.C. de 1768 que establecía como «necesaria e indispensable la enseñanza a toda clase de jóvenes de Gramática, Retórica, Geometría y Artes».

98 BNP, MC, D 1106, Expediente promovido por el rector del Convictorio de San Carlos de la ciudad de Huamanga, Dr. Manuel Renteros sobre la no admisión de estudiantes capistas en ese centro de enseñanza, Huamanga, enero de 1823.

99 Preveían la creación de ocho cátedras: Escritorio, Filosofía, Derecho, Derecho Eclesiástico, Medicina, Religión, Bellas Artes y Lenguas, Archivo del Instituto Riva Agüero, Fondo Denegri Luna, 1419, Documentos de la Academia Lauretana de Ciencias y Artes de Arequipa, 9 de marzo de 1821-2 de julio de 1829. Oficio de Pio Tristán, Evaristo Gómez Sánchez y Manuel Zenteno al excelentísimo ayuntamiento constitucional de Arequipa, 2 de junio de 1823. Por aquel entonces Pío Tristán había regresado a Arequipa y se implicó en varios proyectos liberales en su ciudad natal. 
minario, reformado por el obispo José Chávez de la Rosa, o por determinados miembros de órdenes religiosas. Desde fines del s. XVIII el cabildo había solicitado a la Corona el privilegio de fundar una Universidad y no se perdió la oportunidad de insistir ante las Cortes en el primer liberalismo, cuando se incluyó en las instrucciones al diputado regional Mariano Rivero ${ }^{100}$. Sin embargo fue al abrigo de las nuevas competencias, cuando el ayuntamiento encontró un resquicio que le permitió actuar de forma autónoma y priorizar la educación superior en la ciudad. La Academia Lauretana puede considerarse como el agente clave en la difusión del saber y las ideas liberales en Arequipa.

Entre tanto, las Cortes aprobaron el 29 de junio de 1821 el Reglamento General de Instrucción Pública, que establecía tres niveles educativos. Los ayuntamientos constitucionales pasaban a tener competencias directas en la primera enseñanza, aunque las diputaciones provinciales debían velar para que se implementaran escuelas en los pueblos de su demarcación, sobre todo en los que tuvieran menos de 100 vecinos, y fijar los sueldos y las jubilaciones de los maestros. La segunda enseñanza debía permitir acceder posteriormente a estudios profesionalizadores, que se impartirían en los centros de tercera enseñanza. Los centros de segunda enseñanza o universidades de provincia se crearían, dentro del virreinato peruano, en Cusco, Arequipa y Huamanga, además en Lima y Trujillo, ciudades que se incluían en la norma, a pesar de ser ya independientes. La tercera enseñanza se podría cursar en las universidades de Lima y Cusco y en las escuelas especiales de Medicina, Cirugía y Farmacia, Veterinaria, Nobles Artes, Comercio, Astronomía y Navegación que se preveía crear en Lima ${ }^{101}$. Al conocerse el decreto en el Cusco, el ayuntamiento pedía en abril de 1822 su publicación y que, en tanto se creaba la prevista universidad de provincia, se habilitara para conferir grados de Derecho Civil a la Universidad del Colegio de San Antonio ${ }^{102}$.

100 Las instrucciones de 1809 se hallan insertas en la Causa de Estado instruida contra Mariano Rivero acusado de defender la independencia de las colonias americanas, Archivo Histórico Nacional (AHN), Consejos, 6299, exp. 1, 1814/15.

101 Decreto LXXXI de 29 de junio de 1821, Reglamento General de Instrucción Pública, Colección de los decretos..., 1821, VII: 362-381. La nueva ley daba respuesta en parte a una de las reivindicaciones más recurrentes entre los diputados americanos, como muestran las peticiones de creación de centros de educación superior elevadas por Querétaro, Puebla, Coahuila, San Salvador, Panamá, Costa Rica, Chiapas, Buenos Aires y Charcas, referencias en Anna, 1986: 120-121.

102 ARC, LA, Libro 31, Oficio del Ayuntamiento al Pío Tristán, Cusco, 24 de abril de 1822. El ayuntamiento del Cusco había propuesto poco antes que se impartieran estudios de Derecho Civil, para poder desvincularse de la universidad de Huamanga. Además instó a la creación de dos escuelas públicas, una de las cuales incluyera una «clase de latinidad», que de- 


\section{LAS HACIENDAS LOCALES EN TIEMPOS DE LIBERALISMO Y DE GUERRA}

Las finanzas locales y su gestión se vieron afectadas tanto por el hecho de que se asignaran buena parte de las competencias de Hacienda a la Diputación Provincial - encargada de la distribución y control entre los distintos ayuntamientos de su demarcación de las cargas fiscales ordinarias o extraordinarias ${ }^{103}$ - , como por la coyuntura bélica, que condicionó aún más si cabe la ingerencia del Jefe Político de la Provincia al imponer levas constantes y crecientes exigencias de contribuciones numerarias y de insumos.

El sistema liberal doceañista introdujo varios cambios en las haciendas locales, como fueron: la organización de los bienes comunales en bienes de propios y arbitrios; la gestión y cobranza del mojonazgo reducida al espacio urbano; la venta de terrenos baldíos; la aprobación y abono con cargo al erario municipal de los sueldos de determinados funcionarios locales — alcaide, vacunador, maestros y maestras de primeras letras, capellán - o del juez de letras competente ${ }^{104}$. El talón de Aquiles del nuevo sistema municipal fue la desproporción creciente entre las rentas y los gastos.

Sabemos poco sobre las rentas de propios y arbitrios de las ciudades que nos ocupan, antes y durante el periodo constitucional. Solo para el caso de Arequipa disponemos de una valoración tentativa ${ }^{105}$. Los ingresos anuales en concepto de propios ascendían a 66.332 pesos, producto de los réditos de varios censos impuestos sobre fincas urbanas y rústicas, más 3.317 pesos de los arrendamientos a comerciantes y escribanos de 39 tiendas distribuidas por la ciudad. En concepto de arbitrios se ingresaban unos 10.848 pesos anuales ${ }^{106}$, destinados en parte a abonar 3.748 pesos -525 pesos en réditos anuales

berían financiarse del producto de la judicatura de aguas y fiel ejecutoría, Ibidem, Cusco, 27 de octubre de 1821,21 y 23 de enero de 1822 .

103 Los ayuntamientos estaban obligados a presentar sus cuentas para su revisión y aprobación a la Diputación Provincial, en tal sentido hay varios apuntes en las actas del Cusco, como por ejemplo los relativos a la remisión de las relativas a 1821-1822, ARC, Libro 32, sesión de 8 de marzo y 7 de junio de 1823.

104 ARC, LA, Libro 31, Oficio del Ayuntamiento Constitucional del Cusco al Superior Tribunal, julio 1821; Libro 32, sesión de 14 de junio de 1823.

105 BNP, MC, D 8483, Estado de los propios y arbitrios de Arequipa, sus inversiones y deudas pendientes con otras noticias conducentes a su perfecto conocimiento. Creación de la Academia de Ciencias y Artes, sus fondos y temeraria persecución, Arequipa, 20 de enero de 1825 .

106 Incluían diversas tasas sobre la molienda de harinas, derechos de puesto y sombra en los portales a los vendedores de la plaza mayor, a las cargas que ingresaban en la ciudad y el ejercicio de juez por turno entre los regidores en el coliseo de gallos. 
de varios censos ${ }^{107}, 2.917$ pesos en salarios ${ }^{108}$ y 302 pesos en gastos diversos ${ }^{109}$-.

Uno de los capítulos más complejos y costosos para los ayuntamientos fue la gestión de los hospitales urbanos, sobre todo cuando al socaire de la aplicación, a partir de mayo de 1822, del Soberano Decreto de 25 de octubre de 1820 , relativo a la reforma de las órdenes regulares ${ }^{110}$, les fueron traspasados los establecimientos que habían sido atendidos por conventos supresos por contar con menos de ocho miembros. Tal fue el caso de los hospitales de la Almudena y el de San Bartolomé (o de San Juan de Dios) en el Cusco, y los respectivos de San Juan de Dios en Huamanga ${ }^{111}$ y Arequipa. Hubo que nombrar ecónomos laicos, atender los salarios del personal y especialistas médicos, y también las necesidades de mobiliario, ropa, alimentos y medicinas ${ }^{112}$. En Cusco, además, las autoridades locales tuvieron que organizar y tutelar un hospital de presidiarios y reos dentro de la cárcel nacional ${ }^{113}$, y en Arequipa se exigieron 3.000 pesos a su ayuntamiento para crear un hospital militar ${ }^{114}$.

Entre las crecientes obligaciones de los ayuntamientos no fue menor la de costear los viajes y dietas de los diputados a Cortes. Durante el Trienio Liberal se volvió a plantear un problema que ya había tenido un lugar destacado durante el primer liberalismo, el resolver qué partidas de ingresos de propios y arbitrios podían destinarse a tal fin, más cuando el aumento de competencias y las necesidades bélicas situaban a las haciendas locales en estado crítico. Con todo Tarma, Huancavelica y Huamanga lograron recursos suficientes para que

107 Por un total de 10.500 pesos de principal a abonar a la capilla del Coro de la Catedral, la Curia, San Francisco o San Juan de Dios del Cusco.

108 Teniente asesor, médico, capellán, vacunador, maestros de niños y niñas, maestro de gramática, portero, mayordomo tesorero, escribano, escribiente, carcelero.

109 Fiestas, misas de acción de gracias durante las elecciones, iluminación, papel y gastos de escritorio o pregonero.

110 ARC, Real Audiencia, Administrativo, 177, 1821-1822, José de La Serna a la Audiencia Constitucional, Cusco, 11 de mayo de 1822.

111 Ante el expediente elevado por el provisor y vicario general del obispado de Huamanga, el virrey La Serna le recordaba en respuesta de 2 de diciembre de 1823 que la administración y gestión del hospital de San Juan de Dios era competencia del Ayuntamiento Constitucional tal y como se establecía en el artículo 321 de la Constitución y en el Decreto de Cortes de 23 de junio de 1813. BNP, MC, D 786.

112 En el Cusco se exigió una fianza de 4.000 pesos al administrador del hospital de la Almudena, lo que complicó su selección. Las cuestiones relacionadas con los hospitales fueron tratadas en sucesivas sesiones del ayuntamiento, ARC, LA, Libro 32, sesiones de 16 de diciembre de 1823, 10, 20, 21 y 29 de enero de 1824, 5, 14, 21 de febrero y 6 de marzo de 1824 .

113 ARC, LA, Libro 32, sesión de 6 de setiembre de 1823.

114 AMA, LACA 30, 1824-1825, sesión de 12 de enero de 1824. 
sus diputados se incorporaran a las Cortes ${ }^{115}$. El 28 de junio de 1822 el virrey La Serna pedía a los diputados electos para las legislaturas de 1822 y 1823 que estuvieran en Arequipa en el mes de setiembre para embarcarse con destino a la Península, y encarecía a los ayuntamientos que aún no habían cumplido tal obligación que aportaran los medios económicos necesarios, según se había fijado en la R.O. de la Gobernación de Ultramar de 25 de febrero de 1813. A principios de julio, el Cusco contestaba que le era imposible disponer de medio alguno y que solo la Diputación Provincial tenía competencias en tal sentido y por tanto podía resolverlo ${ }^{116}$. Fue un tema controvertido que llevó a varias propuestas y reticencias por parte del gobierno virreinal cuando las diputaciones provinciales respectivas propusieron medios económicos susceptibles de ser considerados, según la hacienda virreinal, ilegales o que podían ser destinados a gastos de guerra, al punto que los diputados electos de Arequipa, Cusco y Puno, faltos de recursos, no llegarían a viajar a la Península.

Los costos de la guerra fueron múltiples. Quizás el de más calado, del que no contamos con balance alguno, fue la creación de las Milicias Nacionales, que debían ser, según la legislación vigente, organizadas, sujetas y financiadas por los ayuntamientos constitucionales ${ }^{117}$.

El Ayuntamiento del Cusco evaluó el esfuerzo local para sostener las sucesivas campañas militares entre 1809 y 1821 en 28.000 hombres de leva y 8 millones de pesos en numerario. La perentoria situación militar fue elevando paulatinamente los impuestos y tasas extraordinarias exigidas a la población: medio diezmo real; un $2 \%$ sobre el $16 \%$ que tributaban de alcabalas, que ascendía al $26 \%$ al comerciar en otras provincias; $5 \%$ sobre los beneficios estimados de las fincas urbanas, sin distinción entre propietarios y censualistas ${ }^{118}$; 4 y 2 reales por semestre sobre el tributo a los indios originarios y forasteros

115 José Agustín de Larrea, diputado por Huamanga en la legislatura de 1822-1824, se incorporó el 3 de julio de 1823, Gaceta española, Cádiz, viernes 4 de julio de 1823. La Comisión de Poderes denegó la incorporación de Agustín de Otermin, diputado por Huancavelica, alegando defecto de forma en su acta de elección, Diario de Sesiones de Cortes de 9 de julio de 1823.

116 BNP, MC, D 986 y D 6714.

117 Acuse de recibo de R.O. y Decreto del Virrey s.f. de «formación de las Milicias Nacionales que deberán asegurar la tranquilidad pública», BNP, MR, D 10006, sesión de 27 de noviembre de 1822 .

118 Con carácter general se impuso una contribución de guerra a partir de 1824 del 5\% sobre rentas prediales, industriales y comerciales, que entre otras cosas obligó a levantar un censo de propiedades rústicas, que incluía información relativa a los censos y obras pías que les gravaban. Para Huamanga, BNP, MR, D 10006, sesión de 8 de agosto de 1823; y para Arequipa: BNP, MC, D 11903. Tras el retorno al absolutismo el cabildo de Huamanga preguntaría si una vez desaparecida la Diputación Provincial y dada su limitada jurisdicción, debían ejecutar el impuesto extraordinario. BNP, MR, D 10006, sesión de 29 de abril de 1824. 
respectivamente. Se trataba de poder cubrir el contingente mensual de 20.000 pesos que pesaba sobre el Cusco, destinado al ejército realista ${ }^{119}$. Los años sucesivos trajeron mayores necesidades para cubrir los costos bélicos, al punto

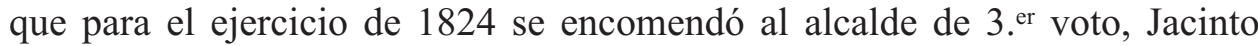
Ccama, como única competencia, el «suministro de bagajes y alojamiento de las tropas nacionales que transiten por su capital» ${ }^{120}$.

En Huamanga, las actas de su ayuntamiento recogen constantes exigencias de la intendencia militar: empréstitos a comerciantes, clérigos, hacendados o autoridades; confiscación de determinadas rentas eclesiásticas - del obispo ausente o de toda la plata labrada de sus iglesias y conventos para ser amoneda$\mathrm{da}-{ }^{121}$; cupos o requisa de ganado, alimentos, sal, leña u ollas, pero también de indios de mita a pesar de la especial prohibición constitucional ${ }^{122}$. En Arequipa, las tropas acantonadas tuvieron asimismo un alto impacto sobre la economía local, tanto por su requisa de animales o exigencia de forrajes. En Cusco y Huamanga se alojaron oficiales y tropas acantonadas o en tránsito, con importantes costos para su vecindario ${ }^{123}$. La cotidianeidad no siempre fue fluida entre militares y civiles, sobre todo por el trato desconsiderado a indios y criados a los que se exigía coactivamente sus servicios en los cuarteles ${ }^{124}$.

\section{EL RETORNO AL ABSOLUTISMO}

En 1823, el gobierno virreinal se encontraba enrocado en el centro y sur andino, sin comunicación directa con la Península debido a la carencia de transportes navales, al punto de que hasta el 13 de mayo de 1824 no se recibió

119 ARC, LA, Libro 31, Representación del Ayuntamiento Constitucional del Cusco de 12 de enero de 1821.

120 Ibidem, Libro 32, sesión extraordinaria de 2 de enero de 1824. Solo adecuar la residencia del virrey, cuando regresó a la ciudad en octubre de 1823, ascendió a 3.000 pesos que debió costear el ayuntamiento de sus rentas, Ibidem, sesión de 6, 27 de setiembre y 23 de octubre de 1823.

121 BNP, MC, D 786, Oficios del virrey La Serna a José Luis Aristizabal, gobernador provisor y vicario general del Obispado, Cusco, 9 de enero de 1822 y 19 de noviembre de 1823.

122 BNP, MR, D 10006, sesiones de 29 de octubre, 4 de noviembre, 4 de diciembre de 1822; 7 de enero de 1823; 19 de enero, 18 de mayo, 19 de junio, 9 de julio y 11 de agosto de 1824.

123 En Huamanga, en junio de 1824, se instalaron dos escuadrones de caballería en los conventos supresos de Santo Domingo y San Francisco y un batallón de infantería en varias casas particulares, Ibidem, sesiones de 4 de mayo y 4 de junio de 1824 .

124 Ibidem, sesiones de 20 de enero de 1823, para el Cusco ARC, Libro 32, sesión de 14 de enero de 1824. 
en Arequipa la correspondencia oficial de la península relativa a $1822^{125}$. Solo se podía obtener información sobre el acontecer político peninsular a través de los buques franceses, ingleses o norteamericanos que siguieron comerciando con los puertos intermedios de la costa de Arequipa y Arica ${ }^{126}$, o por intermedio de los medios de comunicación patriotas. La noticia de que España había vuelto al absolutismo se conoció a través de la Gaceta de Buenos Aires, aunque fue la presión política del general Pedro Antonio de Olañeta, lo que obligó al virrey La Serna a derogar la Constitución en el Perú, y liquidar el entramado institucional liberal. Y, por lo tanto, quedaron suprimidos a nivel regional y local los jefes políticos superiores de la provincia, diputaciones provinciales y ayuntamientos constitucionales.

El retorno al absolutismo supuso la vuelta inmediata al sistema de intendencias y a los cabildos perpetuos. Las órdenes de cese de los respectivos ayuntamientos constitucionales se sucedieron con pocos días de diferencia durante el mes de marzo de 1824: el del Cusco el día 13127, el de Arequipa el $18^{128}$ y el de Huamanga el $24^{129}$. La disposición tuvo inmediatas consecuencias. El Cusco volvió a denominarse «muy Noble Leal y Fidelísima Gran Ciudad del Cusco cabeza de estos Reynos y Provincias del Perú» ${ }^{130}$, se imprimieron varios ejemplares de la «antigua fundación de esta Capital por los primeros españoles», texto extraído del primer Libro de Actas del Cabildo, «para conservar y perpetuar en cualquiera vicisitud de los tiempos» ${ }^{131}$, y en la festividad de Santiago Apóstol, el 25 de julio, volvieron a desfilar por la ciudad los cabildos de españoles y de indios, el primero presidido por el alcalde de $1 .{ }^{\text {er }}$ voto y alférez real, Mariano Campero, y el segundo por Matías Castro Guaypartopa, junto a los 24 electores representantes de las panacas incaicas, portando el estandarte real de los nobles indios de las 8 parroquias $^{132}$. La representación indígena solo fue posible luego que instaran una solicitud específica, que incluía poder elegir los 14 electores cuyas representaciones habían quedado

125 AMA, LACA 30, 1824-5, sesión de 3 de junio de 1824.

126 En tal sentido recordemos que cuando el entonces brigadier Baldomero Espartero fue enviado a la Península por el virrey La Serna, partió del puerto de Quilca el 5 de junio de 1824, llegando a Cádiz el 12 de octubre de 1824. Regresó al Perú vía Burdeos el 9 de diciembre de 1824, llegando a Quilca el 4 de mayo de 1825. Tras ser preso se le permitiría regresar a España, vía Burdeos, donde arribó en noviembre de 1825 .

127 ARC, LA, Libro 33, sesión de 13 de marzo de 1824.

128 AMA, LACA 30, 1824-1825.

129 BNP, MR, D 10006.

130 ARC, LA, Libro 33, sesiones de 13 y 14 de marzo de 1824.

131 Ibidem, sesión de 11 de junio de 1824.

132 Amado, 2002: 236. 
vacantes desde 1815 y volver a desfilar el cabildo pleno tras el impasse del periodo constitucional ${ }^{133}$.

En Arequipa el cabildo se aprontó, junto a otras medidas, a retirar la subvención a la Academia Lauretana, exigiendo al virrey su supresión o cuanto menos la reforma de sus constituciones en lo referente a su adhesión a los principios constitucionales ${ }^{134}$.

El desconcierto planeó entre los vecinos. Si unos creían en la posibilidad de que se mantuviera el mundo colonial de viejo cuño, otros se desencantaron cuando consideraron que el Rey había traicionado dos veces los principios constitucionales, y conscientes de que un tiempo se acababa, observaban desde la retaguardia cómo se aceleraban los acontecimientos militares, que cada vez más afectaban a las tres ciudades, expectantes ante el nuevo orden republicano que se había impuesto en el Perú independiente.

Huamanga fue liberada por las tropas patriotas a fines de agosto de $1824 \mathrm{y}$ la ciudad pasó a denominarse «la muy Noble y Libre Ciudad de San Juan de la Frontera de Huamanga» ${ }^{135}$, hasta que Bolívar la rebautizó como Ayacucho. El 25 de agosto de 1824 se procedió a la elección de alcaldes, regidores y síndicos, quienes juraron su cargo al día siguiente ante el coronel del ejército libertador de Colombia, Ramón Estonba ${ }^{136}$.

En setiembre se tuvo que afrontar en Cusco el alojamiento de seis batallones de los Ejércitos del Norte y del Sur ${ }^{137}$, el mayor contingente acantonado jamás en la ciudad. Iban camino al que sería el último acto de la guerra, la batalla de Ayacucho. El 17 de diciembre se recibió la noticia de la derrota definitiva y el 26 entró entre honores el nuevo prefecto, Agustín Gamarra. Recibido por las diversas corporaciones locales, desfiló entre arcos triunfales, banderas de la libertad y puñados de mixturas de flores y dinero tirados al aire, entre vítores jubilosos de Viva la Patria, la Independencia y la libertad del Perú. El año de 1824 se cerró con el nombramiento por parte de Gamarra de la primera municipalidad republicana, cuyos integrantes juraron por Dios y por la Patria reconocer la Independencia del Perú ${ }^{138}$. El cabildo de indios nunca volvió a ser

133 ARC, Intendencia, Gobierno Virreinal, 160, 1823-24, Expediente sobre que se continúe en esta capital el paseo del Pendón Real en las Visperas y días del Apóstol Señor Santiago y se nombre un Comisario General que debe haber, completándose el número de los 24 electores que faltan, en el cuerpo de cabildo de Yndios nobles de las 8 Parroquias de esta Gran Ciudad del Cusco, 1824.

134 Paz-Soldán, 1862: 78. Ballón y Quiroz, 1999.

135 BNP, MR, D 10006, sesión de 1 de setiembre de 1824.

136 Ibidem, sesión de 26 de agosto de 1824.

137 ARC, LA, Libro 33, sesión de 24 de setiembre de 1824.

138 Sus miembros fueron: Pablo Astete y Juan Tomás Moscoso alcaldes, Vicente Peralta, 
electo, ni menos a desfilar cívicamente. Era el inició de un tiempo en que los nobles indígenas fueron deviniendo en objeto de curiosidad para viajeros extranjeros, lejos de su papel de elites nobiliarias con un papel protagónico en el gobierno señorial indígena y en la sociedad colonial ${ }^{139}$.

El 24 de diciembre de 1824, el mariscal de campo Pío Tristán y Moscoso juró ante los santos evangelios y en presencia del intendente, el Cabildo de Arequipa y el resto de las corporaciones seculares, regulares y los oficiales del ejército, el cargo de virrey y capitán general, puesto para el que había sido nombrado por el Real Acuerdo y la Audiencia territorial del Cusco el 16 de diciembre ${ }^{140}$. El 30 de diciembre se proclamaba la Independencia y se planificaba la transferencia de poderes al coronel José Francisco Otero del Ejército Unido y los actos de su recibimiento: izar cuatro banderas en alusión a la independencia y libertad de Colombia, Perú, Buenos Aires y Chile y engalanar las calles por donde desfilaría la comitiva, desde la Pampa de Cevallos hasta la Casa de Gobierno. El último día del año se acordó postergar la elección de cargos municipales al «nuevo plan legislativo de nuestra libertad e independencia» y que, entre tanto, el cabildo mantuviera sus competencias para «conservar el orden público» ${ }^{141}$. La ciudad todavía vivió con zozobra los últimos ecos de la guerra, cuando el 2 de enero de 1825 se convocó a los comisarios para que se acuartelaran con los vecinos de honor de sus manzanas en el cuartel de Santiago, ante los temores de que les alcanzara la sublevación ocurrida entre la tropa sita en el puerto de Quilca ${ }^{142}$. Eran días aciagos, en los que tras la derrota de Ayacucho los militares capitulados hacían escala en Arequipa, camino de la costa en pos de algún transporte naval que les permitiera regresar a la Península. El Cabildo dispuso su alojamiento en uno de los tambos, arrendado a su costa a tal fin, y en el convento de San Francisco ${ }^{143}$.

Miguel Coraza, Pedro Astete, Diego Calbo, Francisco Artajona, Agustín Cosio y Alzamora, Francisco Pacheco, Ramón Dianderas, Pablo de la Mar y Tapia, Juan Egidio Garmendia, Felipe Loaiza, Manuel Orihuela, Isidro Echegaray, Francisco Tejada y Luis Arteaga regidores, y Toribio de la Torre y José Maruri de la Cuba, síndicos procuradores, Ibidem, sesiones de 21, 26 y 31 de diciembre de 1824 .

139 La especial atención que le dedicaron los viajeros extranjeros, la «indiferencia de la república» y un mundo en ocaso son ideas desarrolladas con relación a Justo Sahuaraura por Flores, 2001.

140 AMA, LACA 30, 1824-1825, sesión de 24 de diciembre de 1824.

141 Ibidem, sesiones de 30 y 31 de diciembre de 1824.

142 Ibidem, sesión de 2 de enero de 1825.

143 Por si fuera necesario, se ordenó a los conventos de San Agustín, la Merced y Santo Domingo que estuvieran dispuestos para alojarles, AMA, LACA 30, sesión de 10 de enero de 1825 . 


\section{CONCLUSIONES}

El proceso abierto en 1820 supuso la experiencia más prolongada de régimen local representativo que había existido hasta entonces en el Virreinato del Perú. Se dieron al menos cuatro elecciones consecutivas a alcaldes y regidores, más las preceptivas a diputados provinciales y a Cortes.

El modelo de organización y representación política de base local, ha sido considerado por autores como Chiaramonti la semilla desde donde se proclamó la Independencia en un modelo cuasi galáctico, destacando el papel de los respectivos alcaldes al tomar la iniciativa política, un proceso que fue el reflejo «más que de una independencia nacional» de una «independencia municipal» ${ }^{144}$. Entendemos que tal propuesta nos puede ayudar a entender el proceso abierto en el Perú independiente, pero necesitamos pensar con más detenimiento sobre los cambios y continuidades en las regiones que siguieron sujetas al control colonial español y su trascendencia en la temprana república peruana.

Acudiendo a la consulta de fuentes de los propios ayuntamientos hemos demostrado que se aplicó la Constitución de 1812 en los territorios realistas entre 1820 y marzo de 1824 , donde se eligieron y funcionaron instituciones regionales y locales representativas. En consecuencia el Trienio Liberal tuvo plena vigencia en el virreinato del Perú. Una coyuntura dominada por la guerra, se caracterizó por cambios profundos en la concepción del poder basado en la división de poderes, la abolición del complejo entramado político del absolutismo, y la introducción de un modelo de gobierno representativo en lo local y provincial, que daría cuotas significativas de autogobierno y autonomía a los habitantes de Arequipa, Cusco y Huamanga.

Cuando los españoles fueron derrotados militarmente, hombres que habían ocupado puestos de gobierno bajo el liberalismo hispano en Arequipa ${ }^{145}$, Cusco o Huamanga, asumirían posiciones relevantes en la temprana república, como fue el caso de Pío Tristán, al que nos hemos referido como jefe político de la provincia del Cusco, miembro activo de la Academia Lauretana durante su retiro en Arequipa y como el último virrey del Perú, y que tras la Independencia sería nombrado prefecto de Arequipa por Santa Cruz, y ocuparía el puesto de ministro de estado en 1836, para culminar su carrera política como presidente del estado Sud-Peruano (1838-1839).

Varias cuestiones son de difícil resolución en el actual estado de nuestros conocimientos. Entre 1820 y 1824 mudó sustancialmente la administración lo-

144 Chiaramonti, 2007.

145 El papel destacado de actores liberales arequipeños con el republicanismo de la temprana república se señala en el artículo de McEvoy incluido en este dossier. 
cal en el Virreinato del Perú. El sistema representativo fue la punta de lanza de una nueva concepción del poder local, que acercaba a los vecinos a la participación política y a la resolución cercana de sus problemas y demandas. La pregunta que surge es: ¿en qué medida la derogación de la Constitución por Fernando VII, y la liquidación del segundo liberalismo, no aceleró el fín de la guerra y la pérdida del Virreinato? Si la respuesta fuera afirmativa, quizás se podría entender porqué el influjo del liberalismo gaditano puede rastrearse en el temprano constitucionalismo republicano peruano y porqué tantos hombres pudieron hacer el tránsito desde las filas del liberalismo hispano y la participación en las instituciones locales y provinciales del Trienio Liberal a puestos de responsabilidad en la naciente República peruana. Pero también nos ayudaría a comprender que muchos de los que dejaron de ser nacionales para ser $p a-$ triotas, lo hicieron porque Fernando VII había traicionado por segunda vez sus obligaciones como monarca constitucional, despojándoles de derechos y deberes que el liberalismo les había concedido y que habían ejercido con prácticas de gobierno representativo. Ya no restaba incertidumbre alguna, la única vía política posible era implicarse en construir la naciente república peruana.

\section{BIBLIOGRAFÍA}

Amado, Donato, «El alférez real de los incas: resistencia, cambios y continuidad de la identidad indígena», Jean-Jacques Decoster (ed.), Incas e indios cristianos. Elites indígenas e identidades cristianas en los Andes coloniales, Cusco, Asociación Kuraka, 2002: 221-249.

Anna, Timothy E., España y la Independencia de América, México, FCE, 1986.

Annino, Antonio, «Cádiz y la revolución de los pueblos mexicanos, 1812-1821», en Historia de las elecciones en Iberoamérica, siglo XIX, Buenos Aires, FCE, 1995: 177-226.

Ballón Lozada, Héctor y Quiroz Paz Soldán, Eusebio, Academia lauretana de ciencias y artes de Arequipa, Arequipa, Colegio de Abogados de Arequipa, 1999.

Brown, Kendall, Borbones y aguardiente. La reforma imperial en el sur peruano: Arequipa en vísperas de la Independencia, Lima, BCRP-IEP, 2008.

Castillo, Francisco, Figallo, Luisa J. y Serrera, Ramón María, Las Cortes de Cádiz y la Imagen de América. La visión Etnográfica y Geográfica del Nuevo Mundo, Cádiz, Universidad de Cádiz, 1994.

Castro, Concepción de, La Revolución Liberal y los municipios españoles, Madrid, Alianza Universidad, 1979. 
Chambers, Sarah C., De súbditos a ciudadanos: honor, género y política en Arequipa, 1780-1854, Lima, Red para el Desarrollo de las Ciencias Sociales en el Perú, 2003.

Chiaramonti, Gabriela, Ciudadanía y representación en el Perú (1808-1860). Los itinerarios de la soberanía, Lima, UNMSM-ONPE-SEPS, 2005.

Chiaramonti, Gabriela, «De marchas y contramarchas: apuntes sobre la institución municipal en el Perú, 1812-1861», Araucaria, 18 (2007): 150-170.

Colección de los decretos y órdenes generales expedidos por las Cortes Ordinarias de los años 1820 y 1821, en el segundo periodo de su diputación que comprende desde 25 de febrero hasta 30 de junio del último año, Madrid en la Imprenta Nacional, 1821 , t. VII.

Colección de los decretos y órdenes generales expedidos por las Cortes Extraordinarias que comprende desde 22 de setiembre de 1821 hasta 14 de febrero de 1822, Madrid en la Imprenta Nacional, 1822, t. VIII.

Colección Documental de la Independencia del Perú (CDIP), XXII, Gobierno virreinal del Cuzco, 3, Lima, Comisión Nacional del Sesquincentenario de la Independencia del Perú, 1973.

Condori, Víctor, «Los efectos económicos de la Independencia en Arequipa: 18201824», Carlos Contreras, Cristina Mazzeo y Francisco Quiroz (eds.), Guerra, finanzas y regiones económicas en la historia económica del Perú, Lima, CERP-IEP, 2010: 173-218.

Dean, Carolyn, Los cuerpos de los Incas y el cuerpo de Cristo. El Corpus Christi en el Cuzco Colonial, Lima, UNMSM-Banco Santander Central Hispano, 2002.

Escandell, Neus, Producción y comercio de tejidos coloniales. Los obrajes y chorrillos del Cusco, 1570-1820, Cusco, CBC, 1997.

Fisher, John, «Royalism, Regionalism, and Rebellion in colonial Perú, 1808-1815», HAHR, 59 (2) (1979): 232-257.

Fisher, John, El Perú borbónico, 1750-1824, Lima, IEP, 2000.

Fisher, John, «Redes de poder en el Virreinato del Perú, 1776-1824: los burócratas», Revista de Indias, 236 (Madrid, 2006): 149-164.

Flores Espinoza, Javier, «La añoranza del pasado. Justo Sahuaraura Inca y sus Recuerdos de la monarquía peruana», Justo Apu Sahuaraura Inca, Recuerdos de la Monarquía peruana o bosquejo de la historia de los Incas. Compendio Breve, Lima, Fund. Telefónica, 2001: 13-46.

Gamio Palacio, Fernando, La municipalidad de Lima y la emancipación, 1821, Lima, Sanmartí y Cía., 1944.

Garrett, David T., Sombras del Imperio. La nobleza indígena del Cuzco, 1750-1825, Lima, IEP, 2009. 
González, Enrique, Gutiérrez, Yuri y Urrutia, Jaime, La ciudad de Huamanga: espacio, historia y cultura, Lima, UNSCH, Concejo Provincial de Huamanga, Centro Peruano de Estudios Sociales, 1995.

Hernández, Elizabeth, «Una columna fortísima del altar y del trono: Pedro Gutiérrez de Cos, obispo de Huamanga de Puerto Rico (1750-1833)», Hispania Sacra, 60/122 (Madrid, 2008): 531-555.

Igue, José Luis, Bandolerismo, patriotismo y etnicidad poscolonial: los morochucos de Cangallo, Ayacucho en las guerras de Independencia, 1814-1824, Lima, PUCP, Tesis de Licenciatura, 2008.

Martínez, Santiago, Alcaldes de Arequipa desde 1539 a 1946, Arequipa, Tip. Acosta, 1946.

Martínez Pérez, Fernando, Entre la confianza y responsabilidad. La justicia del primer constitucionalismo español (1820-1823), Madrid, Centro de Estudios Políticos y Constitucionales, 1999.

Martínez Riaza, Ascensión, «Las diputaciones provinciales americanas en el sistema liberal español», Revista de Indias, 196 (Madrid, 1992): 647-691.

Morell Ocaña, Luis, «El municipio constitucional y la Instrucción de 1813», El Municipio Constitucional, Madrid, Ministerio de Administraciones Públicas, Instituto Nacional de Administración Pública, 2003: 121-146.

Mörner, Magnus, Perfil de la sociedad del Cuzco a fines de la colonia, Lima, Universidad del Pacífico, 1978.

Ortego Gil, Pedro, «La instrucción para el gobierno económico-político de las provincias de Ultramar», Anuario Mexicano de Historia del Derecho (México, 2002): 343-495.

Paniagua, Valentín, Los orígenes del gobierno representativo en el Perú. Las elecciones (1809-1826), Lima, PUCP-FCE, 2003.

Paz-Soldán, José G., Anales universitarios del Perú, Lima, Imprenta de la Época por J. E. del Campo, 1862.

Peralta, Víctor, «Los inicios del sistema representativo en el Perú: ayuntamientos constitucionales y diputaciones provinciales (1812-1815)», Marta Irurozqui (ed.), La mirada esquiva. Reflexiones históricas sobre la interpretación del estado y la ciudadanía en los Andes (Bolivia, Ecuador y Perú). Siglo XIX, Madrid, CSIC, 2005a: 65-92.

Peralta, Víctor, «De absolutistas a constitucionales. Política y cultura en el gobierno del virrey Pezuela (Perú 1816-1820)», J. E. Rodríguez, O. (coord.), Revolución, independencia y las nuevas naciones de América, Madrid, Fundación MAPFRE Tavera, 2005b.

Peralta, Víctor, «La transformación inconclusa. La trayectoria del liberalismo hispánico en el Perú (1808-1824)», Ayer, 74/2, (Madrid, 2009): 107-131. 
Pérez Núñez, Javier: «Acerca del gobierno y administración territorial en el régimen constitucional gaditano», Revista de Estudios Políticos, 144 (Madrid, 2009): 143-165.

Sala i Vila, Núria, «De Inca a indígena: cambio en la simbología del sol a principios del siglo XIX», Allpanchis, II/35-36 (Cusco, 1990): 599-633.

Sala i Vila, Núria, «La Constitución de Cádiz y su impacto en el gobierno de las comunidades indígenas en el virreinato peruano», Boletín Americanista, 42-43 (Barcelona, 1992): 51-70.

Sala i Vila, Núria, «Ayuntamientos constitucionales y Justicia conciliatoria durante el Trienio Liberal en Perú (1820-1824): el caso de Huamanga», ponencia presentada al II Coloquio hacia el Bicentenario de la Independencia del Perú, Instituto Riva Agüero-Embajada de España-AECID, Lima, 15-16 de noviembre de 2010.

Walker, Charles, De Tupac Amaru a Gamarra. Cusco y la formación del Perú Republicano, 1780-1840, Cuzco, Centro Bartolomé de las Casas, 1999.

Fecha de recepción: 16 de marzo de 2011

Fecha de aceptación: 25 de julio de 2011

\section{The Liberal Triennium in the Peruvian viceroyalty: the constitutional local governments of Arequipa, Cusco and Huamanga, 1820-1824}

This article explores unknown aspects of the re-implantation of representative government in the Vice-Royalty of Peru during the Liberal Triennium. To this end, three cities which remained loyal to the Crown until a very late period have been chosen: Cusco, Huamanga and Arequipa. Consultation of local records from the three corporations has made it possible to reconstruct three examples of local power through electoral processes, the composition of ayuntamientos (local government councils) and analysis of the limits of their competence. The article shows that Vice-Roy La Serna governed in accordance with the Constitution of 1812 and displays the existence of processes of change and continuity between Spanish ayuntamientos and Peruvian municipalities, given that some individuals and formulae inherited from the Hispanic institutions remained in place over time.

KeY Words: Liberal Triennium; Peru; constitutional local governments; Arequipa; Cusco; Huamanga. 